\title{
Una aproximación histórica al arte rupestre prehispánico de la sierra de El Alto-Ancasti (Provincia de Catamarca, Noroeste Argentino)
}

\section{An historical approach to the prehispanic rock art of El Alto-Ancasti's Sierra (Catamarca Province, Northwest Argentina)}

\author{
Lucas Gheco ${ }^{1,2}$ https://orcid.org/0000-0003-4941-1196 \\ ${ }^{1}$ Centro de Investigaciones y Transferencia Catamarca, Consejo Nacional de Investigaciones \\ Científicas y Técnicas - Universidad Nacional de Catamarca. San Fernando del Valle de \\ Catamarca, ARGENTINA. \\ ${ }^{2}$ Instituto de Investigaciones sobre el Patrimonio Cultural, Universidad Nacional de San \\ Martín, Ciudad de Buenos Aires, ARGENTINA. Email: gheco@hotmail.com.
}

\begin{abstract}
Resumen
¿Cómo aproximarnos a los procesos históricos a través de los cuales los paneles rupestres fueron construidos y modificados? ¿Cómo integrar esas historias de pintado/grabado al resto de las prácticas sociales ejecutadas a su alrededor a lo largo del tiempo? Este artículo tiene como objetivo destacar la relevancia de dichos interrogantes y describir una metodología que permite comenzar a responderlos a partir de la combinación de múltiples niveles de análisis con cinco líneas de evidencias diferentes: análisis espaciales, estudios de las superposiciones entre figuras, estudios estilísticos, análisis químicos de las mezclas pigmentarias y excavación estratigráfica de los depósitos sedimentarios en los pisos de los abrigos. Se presentan, a modo de ejemplo, los resultados alcanzados en la investigación del arte rupestre del sitio arqueológico de Oyola, en la Sierra de El Alto-Ancasti del Noroeste Argentino, aunque la articulación metodológica y técnica podría ser útil a la investigación de otros sitios.
\end{abstract}

Palabras claves: arqueología, Oyola, estratigrafía, análisis químicos.

\begin{abstract}
How can we approach the process through which rock art panels have been built and modified? How to connect these histories of painting/engraving with the others social practices performed in the caves though the time? The goal of this article is to remark the importance of these questions and describe a methodology intended to solve them through the combination of multiple levels of analysis, with five different lines of evidence (spatial analysis, overlapping studies, morphologic-stylistic studies, analysis of pigment mixtures and the stratigraphic excavation of the floor's sediments). As an example, we present the results obtained by the application of this methodology to the study of the rock art from El Alto-Ancasti's Sierra; however the methods and techniques could be useful for the research of other sites.
\end{abstract}

Keywords: archaeology, Oyola, stratigraphy, chemical analyses.

Recibido: 9 abril 2018. Aceptado: 23 septiembre 2019 


\section{Introducción}

Desde hace algunos años que la arqueología, al igual que la mayoría de las ciencias sociales, no solo se pregunta por los fenómenos generales de tipo macrosocial o macroanalítico, sino que destaca la necesidad de comprender las prácticas sociales específicas a través de las cuales las personas construyen el mundo y a sí mismas. Esta reorientación teórica significó invertir el eje de causalidad en la tradicional comprensión de los cambios culturales: ya no son los fenómenos generales, masivos, anónimos y hasta inconscientes los que determinan la vida de las personas, sino que son justamente ellas en su accionar situado las que les dan forma y los transforman constantemente (Pauketat, 2001). Sin embargo, en muchos casos, estas elecciones teóricas -en ocasiones vinculadas a los desarrollos de otras disciplinas como la sociología, historia y antropología- no se han traducido en metodológicas arqueológicas específicas a través de las cuales alcanzar esas acciones concretas en donde se articulan las estructuras estructurantes, las contingencias históricas y las elecciones individuales; es decir, las prácticas sociales (Pauketat y Alt, 2005; Moore, 2010).

Las investigaciones sobre los sitios arqueológicos con arte rupestre de los últimos años han transitado, de modo muy resumido, tres sendas principales en términos metodológicos y técnicos: estudios morfológicos, abordajes espaciales y análisis arqueométricos. Los primeros han sido de gran utilidad para avanzar en el conocimiento de la cronología del arte rupestre mediante la identificación de estilos y su conexión con determinados momentos/culturas, al mismo tiempo que han habilitado una pluralidad de discusiones sobre las características políticas, económicas e ideológicas de los grupos en cuestión según los marcos teóricos seleccionados en cada caso (culturalistas, semióticos, funcionalistas, etc.) (Martel, 2010; Basile, 2011). Los estudios espaciales, por su parte, aportaron cuantiosa información sobre las relaciones de los motivos rupestres entre sí-al interior de cada cueva o bloque rocoso-, pero también sobre los vínculos entre los distintos abrigos con arte rupestre y otros sitios arqueológicos, con la posibilidad de aproximarse a la construcción y significación de los antiguos paisajes sociales (Criado-Boado, 1993; Troncoso, 2005, 2008a; Carden, 2008). Por último, las investigaciones arqueométricas han generado un notable avance en el conocimiento de los compuestos utilizados y de las cadenas operativas vinculadas al proceso de producción del arte rupestre, así como han permitido la datación absoluta de los motivos, entre otros aspectos (Fiore, 2009, 2018; López, De la Fuente y Fiore, 2013). En muchos casos, cada uno de estos enfoques, al menos en su aplicación tradicional, ha tendido a destacar las recurrencias, constantes y similitudes entre las pinturas/grabados, definiendo respectivamente "estilos", "estructuras espaciales" y "recetas pictóricas". De tal modo, estas interpretaciones resaltaron la homogeneidad del arte rupestre de una región o de un sitio en términos morfológicos, espaciales o físico-químicos, elaborando explicaciones que privilegiaron la sincronía y la uniformidad frente a los cambios e irregularidades que suponen los procesos históricos.

Ahora bien, ¿cómo aproximarnos a la complejidad y heterogeneidad de los procesos a través de los cuales los paneles rupestres fueron construidos y modificados? ¿Cómo integrar esas historias de pintado/grabado con el resto de las prácticas sociales ejecutadas a su alrededor a lo largo del tiempo? Preguntas sencillas, pero cuyas respuestas exigen que indaguemos en los métodos adecuados para intentar responderlas; interrogantes que nos enfrentan a la necesidad de reorientar nuestras técnicas de estudio con miras a conocer los procesos históricos particulares a través de los cuales las pinturas y grabados $-\mathrm{y}$ probablemente también las personas- fueron generados, transformados, utilizados y significados. Este trabajo no se propone resolver dichos interrogantes sino, más bien, destacar que son relevantes y presentar, a través de un caso de estudio en las montañas boscosas de la sierra de El Alto-Ancasti (Provincia de Catamarca, Noroeste Argentino), algunos caminos metodológicos para avanzar en ese sentido.

\section{Una historia de personas y pinturas}

Desde fines del siglo XIX hasta las últimas décadas del XX, la mayoría de las ciencias sociales se abocaron al estudio de los grandes fenómenos históricos como elementos rectores de la vida social. En ese marco, la investigación de las transformaciones macroeconómicas, grandes revoluciones, invasiones entre naciones, cambios en las políticas estatales y hasta 
de estructuras universales inconscientes en la mente de las personas, solo por mencionar unos ejemplos, fueron algunas de las líneas prioritarias estudiadas. Sin embargo, a partir de la década de 1970, comenzaron a surgir un conjunto de perspectivas teóricas que manifestaron un profundo malestar con las trayectorias que, hasta entonces, habían transitado las diferentes disciplinas sociales $y$, en contraposición, se esforzaron por dar a la experiencia de las personas la importancia sustraída en los procesos sociales masivos, anónimos e inconscientes que por muchos años parecieron ser los únicos en requerir la atención de los investigadores (Revel, 2015). Los desarrollos de la microhistoria italiana, la historia de la vida cotidiana en Alemania, los enfoques interpretativos de la antropología geertziana, las teorías sociológicas de la práctica y la estructuración, por mencionar solo algunos, pueden ser ejemplos de estas posturas críticas que, a pesar de sus diferencias, coincidieron en hacer de las acciones y experiencias de los actores sociales el centro de sus reflexiones. Sin embargo, este volver a las experiencias de las personas no implicó un desplazamiento extremo hacia el vértigo de lo individual, incluso excepcional, sino la convicción de que esas vidas minúsculas también participan activamente en la historia "grande", de la que dan una versión diferente y más compleja (Ginzburg, 2008a, 2008b, 2010; Revel, 2015). Así, la investigación de los casos singulares, aparentes excepciones e historias locales comenzó a exponer otra visión de los fenómenos históricos que, fundamentalmente, recogió las voces y acciones de los "ausentes" de la Historia, constituyéndose no solo en una elección teórica sino también política.

Las investigaciones arqueológicas no estuvieron exentas de estas transformaciones, y ya desde las últimas décadas del milenio anterior numerosos investigadores remarcaron el rol pasivo de las personas -y también de los objetos- en las explicaciones propuestas a partir de los marcos teóricos dominantes hasta entonces (Hodder, 1992; Pauketat, 2001). Más aún, también destacaron la ubicación privilegiada de la arqueología para reconocer las prácticas cotidianas y los eventos concretos a través de los cuales las personas constantemente reproducen y transforman las culturas (Pauketat y Alt, 2005). Sin embargo, como se mencionó, los problemas surgieron al momento de adecuar los nuevos enfoques teóricos con las metodologías y técnicas usualmente empleadas en la disciplina, cuyos resultados tienden a destacar la recurrencia y la uniformidad bajo distintas formas conceptuales ("patrones arquitectónicos", "cánones estilísticos", "tipologías cerámicas", "recetas pictóricas", “estructuras espaciales”, etc.).

Los estudios sobre el arte rupestre no escaparon a estas dificultades y es el objetivo de este artículo presentar, a través de un caso de estudio, una alternativa metodológica para avanzar en el conocimiento de los complejos procesos históricos mediante los cuales los paneles rupestres fueron elaborados y utilizados. A modo de ejemplo, en las próximas páginas se retoman parte de las investigaciones desarrolladas en los sitios con arte rupestre de la sierra de El AltoAncasti, especialmente en los abrigos de Oyola. De modo resumido, esta metodología puede describirse a partir de tres ejes fundamentales: 1) la elección de una escala de observación centrada en las prácticas sociales; 2) la interrelación de múltiples niveles de análisis; y 3) el uso complementario de diferentes líneas de evidencias como recursos para separar, secuenciar y conectar las historias acaecidas en los abrigos con arte rupestre (ver Gheco, 2017, para profundizar en la metodología).

Con respecto al primer punto, el concepto de escala de observación utilizado en este trabajo no se refiere al tamaño del universo estudiado -aspecto que denominamos nivel de análisis-, sino más bien a una elección deliberada sobre cómo analizar los datos, que se vincula a qué es lo que queremos investigar y qué, por lo tanto, implica un punto de vista de conocimiento (Lepetit, 2015). Al hablar de una escala de las prácticas sociales, se pretende centrar la atención y esfuerzos en el análisis del plano de contacto entre las pautas estructurales y las acciones individuales, sin seleccionar a priori un tamaño en particular del universo a investigar. En ocasiones, el usual prefijo micro que acompaña algunas de las perspectivas asociadas al estudio de fenómenos históricos circunscritos y casos particulares -la microhistoria italiana, por ejemplo- ha generado una imagen un tanto confusa en la cual se relaciona esta escala de observación con el análisis de objetos, episodios, espacios o tiempos acotados. Si bien es cierto que la elección de universos restringidos vuelve más factible alcanzar un elevado grado de detalle 
en los datos analizados, y con ello aproximarse a la complejidad que suponen las prácticas sociales, este recorte reducido no implica necesariamente que los resultados sean interpretados en ese sentido. Es decir, el estudio de universos acotados no conlleva por sí mismo una elección centrada en la búsqueda de las prácticas sociales y de las historias locales. Es esa elección de situar en el foco de atención determinados fenómenos, independientemente de la cantidad de datos analizados, lo que se intenta expresar bajo el concepto de escala de observación. Bien se podría emprender este trabajo mediante el estudio de una cueva con arte rupestre o de todas las registradas en una región si, en cada caso, nuestra mirada se concentrara en evaluar los datos en función de las tensiones entre las tendencias generales y los casos particulares; es decir, en el punto donde se pueden vislumbrar algunos aspectos de tales prácticas. Esta elección teórico-metodológica produce una continua desconfianza en las clasificaciones arqueológicas, lo cual invita a modificar constantemente los parámetros sobre los cuales fueron construidas para rastrear, en los desechos y contradicciones de tales agrupamientos, los indicios de las situaciones y fenómenos aparentemente secundarios en la "historia de las recurrencias". ${ }^{1}$

El segundo punto relevante de esta metodología se refiere a la articulación de diferentes niveles de análisis. El carácter fragmentario de los materiales arqueológicos, sumado al deterioro que muchas veces posee el arte rupestre, solo permite reconocer en un mismo nivel o universo de análisis aspectos parciales de las historias de confección y usos de estos abrigos o sitios, aspectos que pueden ser complementados mediante su combinación con otros. Diferentes trabajos han indagado en la posibilidad de articular distintos niveles de análisis (Aschero, 1988; Hernández Llosas, 1985; Nash, 2002; Chippindale, 2004; Troncoso, 2008b). Sobre la base de esos antecedentes, y considerando el problema de estudio, en esta investigación se alternan tres niveles de análisis

1 Con la expresión "historia de las recurrencias" nos referimos al modelo de producción de conocimientos que Ginzburg (2008b) denominó como "galileano", heredado de las ciencias naturales y desde hace muchos ańos en boga en las ciencias sociales. Este modelo se caracteriza por el énfasis en la reiterabilidad, en la cuantificación, en la elaboración de series y tendencias generales. diferentes que expresan relaciones distintas entre resolución e inclusividad:

1. Nivel de abrigo/bloque. Comprende el bloque rocoso, el alero o la cueva. En este nivel interactúan la roca, los motivos pintados y/o grabados a lo largo del tiempo, los paneles, otros vestigios materiales muebles e inmuebles, los hallazgos en las excavaciones de los sedimentos estratificados en el suelo, entre otros aspectos. Este nivel expresa el universo más restringido, en términos espaciales y temporales, y de mayor resolución de datos que se considera en la investigación.

2. Nivel de sitio. Para definir este nivel se retoma la propuesta de Troncoso (2008b), quien denomina como sitio "una discreta unidad definida por la agregación de bloques o paneles con arte rupestre dentro de un área definida en el espacio y segregada espacialmente de otras agregaciones". En esta instancia se incluye, además de los abrigos con arte, el análisis de otros materiales arqueológicos asociados.

3. Nivel de paisaje. Considera la relación entre los distintos sitios con arte rupestre con otros sitios de diversas características dispuestos en su entorno inmediato y más distante en la sierra de El Alto-Ancasti y serranías vecinas.

El tercer y último punto de la metodología propuesta supone la utilización complementaria de diferentes líneas de evidencias (análisis espaciales, de las superposiciones entre motivos, morfológico-estilísticos, análisis químicos de las mezclas pigmentarias y excavaciones estratigráficas) con el objetivo de realizar tres operaciones o ejercicios (separar, secuenciar y conectar) que -creemos- resultan fundamentales para el conocimiento de los abrigos con arte rupestre desde una perspectiva centrada en las prácticas sociales y en los procesos históricos (sensu Pauketat, 2001). Si bien nuestra investigación supone que la realidad es fundamentalmente heterogénea y discontinua, que las leyes sociales son las más excepcionales de las excepciones y que las similitudes entre los fenómenos son posibles de establecer solo si se ponen entre paréntesis sus mayores diferencias, en esta ocasión partimos de un punto diametralmente opuesto en donde, como se expone a continuación, 
el arte rupestre de la sierra de El Alto-Ancasti fue considerado como un fenómeno homogéneo y relativamente sincrónico. A partir de este problema, las líneas de evidencias utilizadas persiguen como finalidad destacar la diversidad del arte rupestre (operaciones de separación o diferenciación), explorar su orden temporal o cronológico (operaciones de secuenciación) e indagar en las formas de asociar evidencias que, a primera vista, parecen situarse en planos desconectados (operaciones de conexión).

Más allá del caso particular expuesto, se espera que el desarrollo metodológico y la combinación de técnicas pueda resultar útil para la investigación de las historias de confección, transformaciones y variados usos de otros sitios arqueológicos con arte rupestre que posean características semejantes.

\section{El arte rupestre de la sierra de El Alto-Ancasti}

Desde mediados del siglo pasado, diversos investigadores emprendieron el estudio del arte rupestre de los faldeos orientales de la sierra de El Alto-Ancasti, en el extremo sureste de la Provincia de Catamarca, Argentina (Figura 1). Más allá de la diversidad en los marcos teóricos adoptados y en las interpretaciones propuestas sobre las pinturas y/o grabados, la lectura detallada de las publicaciones realizadas permite advertir, al menos, dos puntos comunes que, como hilos invisibles, tienden lazos entre los distintos autores y equipos de trabajo.

El primer punto y, quizás, el más importante por su recurrencia y consecuencias interpretativas, se vincula con la atribución uniforme del arte rupestre de la zona a una única cultura -Cultura La Aguada- o a un período histórico en particular-Período Medio o de Integración Regional del NOA (ca. 600-900 DC) - de acuerdo a las similitudes estilísticas advertidas entre algunos motivos rupestres y los diseños característicos de la cerámica de dicha cultura o momento (De la Fuente, 1969, 1979; Segura, 1971; De la Fuente y Arrigoni, 1975; González, 1998; Llamazares, 1999; Gordillo, Baldini, y Kusch, 2000; De la Fuente, Nazar, y Pelli, 2005). Así, los grandes

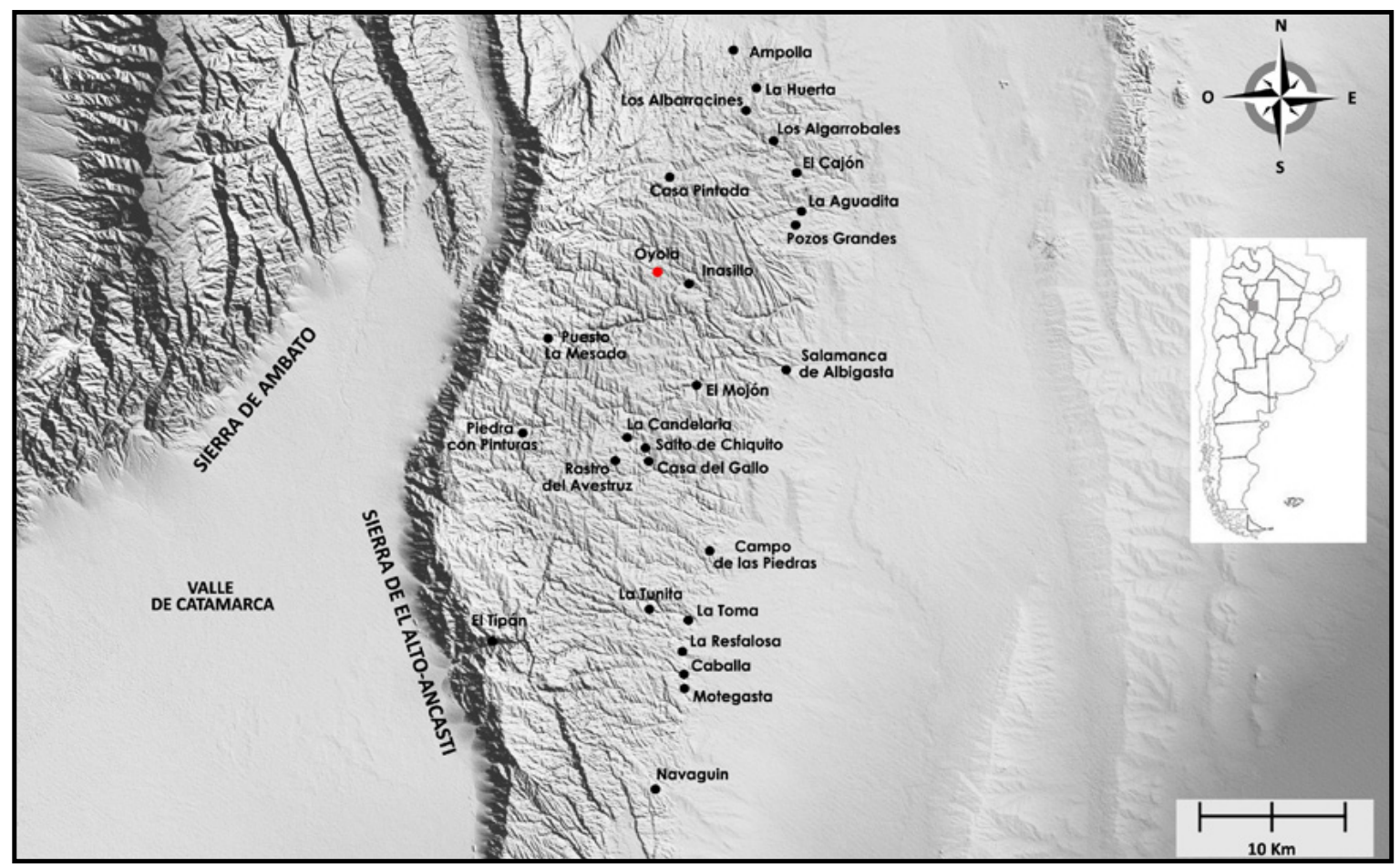

Figura 1. Mapa de la sierra de El Alto-Ancasti.

Se indican los diferentes sitios arqueológicos con arte rupestre documentados hasta 2018. Fuente: Elaboración personal. 
felinos, sacrificadores y presuntos shamanes plasmados en las paredes de las cuevas de La Tunita y La Candelaria - por muchos años los sitios más estudiados de la zona- se convirtieron en los exponentes principales del arte rupestre de la sierra (González, 1977; Schobinger y Gradin, 1983; Nazar, Gheco, y Barot, 2012; Nazar, De la Fuente y Gheco, 2014). Esta primera conclusión no solo otorgó un marco cronológico en el cual interpretar los sitios, sino que también habilitó la extrapolación de toda una serie de inferencias sobre las características políticas, económicas e ideológicas de los grupos en cuestión a partir de los estudios realizados en otras zonas, en ocasiones distantes, como Ambato y Hualfín.

Como segundo punto, y en estrecha conexión con la interpretación anterior, se propuso una funcionalidad ritual de los abrigos con arte rupestre de la zona sustentada en cuatro pilares fundamentales: 1) La ubicación periférica de los sitios con arte rupestre con respecto a los supuestos centros nucleares del Período Medio o de Integración Regional; 2) La disposición de las cuevas y aleros en medio de un espeso bosque de cebiles, árboles con propiedades psicotrópicas cuyo uso ha sido corroborado desde tiempos prehispánicos (Lema et al., 2015); 3) La ausencia en el interior de las cuevas de otros restos arqueológicos, además de las pinturas y/o grabados propiamente dichos; 4) La comprensión de las pinturas plasmadas en las paredes de las cuevas, en algunos casos de danzas y presuntos rituales, como las representaciones de tales actividades ejecutadas en esos espacios (Figura 2) (Segura, 1971; Gramajo y Martínez Moreno, 1978; De la Fuente y Díaz Romero, 1979; Llamazares, 1999). En ese marco, el shamanismo omnipresente y la geopolítica de complementariedad ecológica, centralización política e integración cultural planteada para el Período Medio o, en su defecto, para la Cultura La Aguada, fueron el complemento adecuado para sostener esta interpretación ritual de los sitios con arte rupestre sin la necesidad de indagar en las evidencias materiales que informen sobre las actividades específicas desarrolladas en dichos espacios.

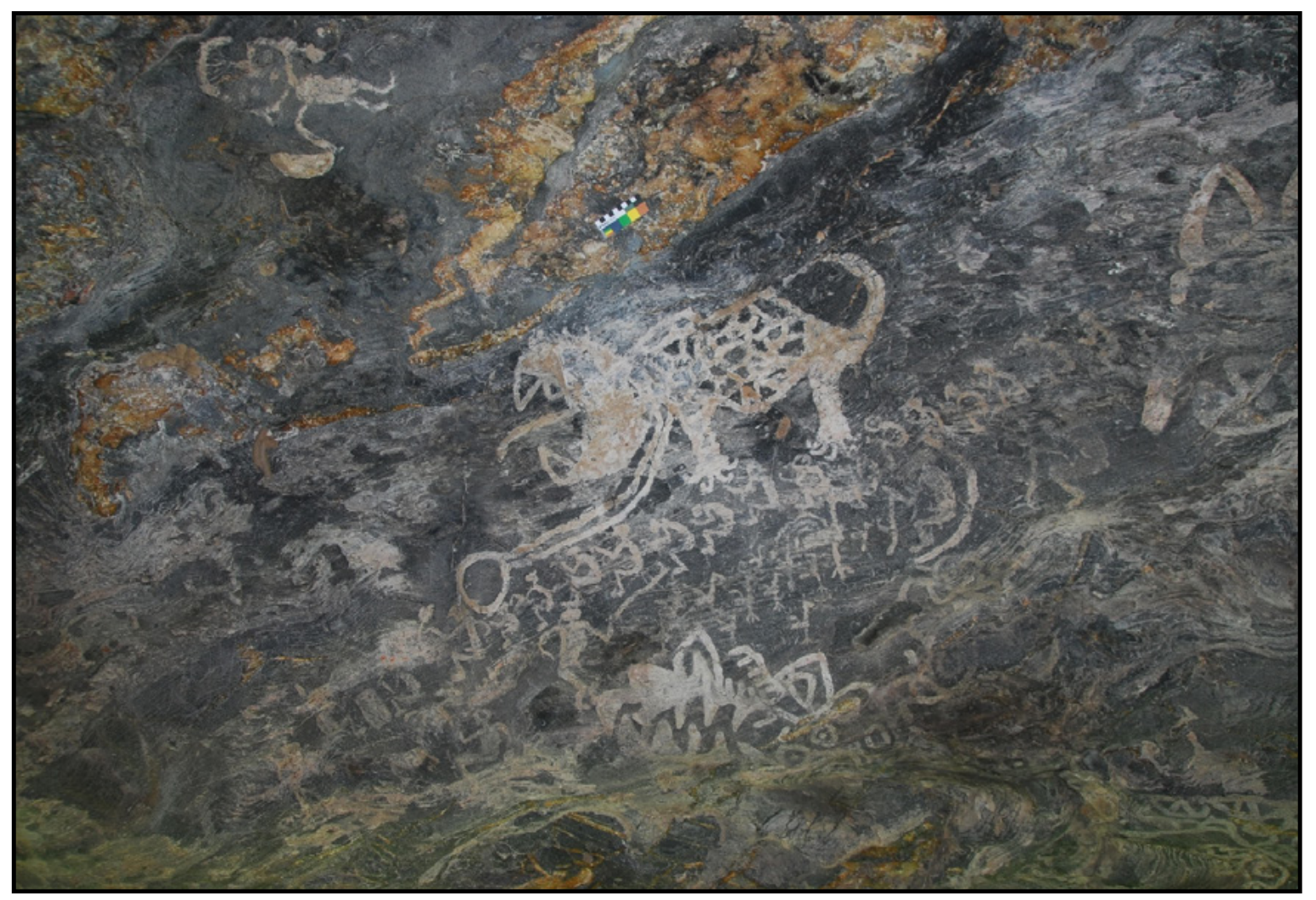

Figura 2. Pinturas rupestres del sitio La Candelaria. Fuente: Autor. 
Aunque en extremo resumidos, los puntos anteriores resultan fundamentales para comprender el doble proceso de homogenización, estilística y funcional, que atravesó el arte rupestre de las serranías orientales de Catamarca a partir de las interpretaciones elaboradas en la segunda mitad del siglo pasado. Sin embargo, también es justo mencionar que fueron los mismos investigadores que remarcaron estas similitudes quienes detectaron los indicios de su heterogeneidad. De esta forma, mencionaron que algunas pinturas no presentaban los diseños tradicionales de la Cultura La Aguada y que podrían corresponder a otros pueblos, culturas o períodos, aunque no ahondaron en el estudio de estas diferencias (De la Fuente, 1969; Segura, 1971; De la Fuente y Arrigoni, 1975; Gramajo y Martínez Moreno, 1982). Incluso la extensión cronológica advertida a partir de las dataciones absolutas de las pinturas de La Candelaria (Hedges et al., 1998), con 500 años de intervalo entre las más antiguas y las más recientes, fue interpretada como una evidencia más para asignación cultural a La Aguada antes que como el puntapié para indagar en la multiplicidad de eventos de pintado y prácticas sociales eclipsados detrás de una interpretación cultural homogénea. ${ }^{2}$

¿Qué sucede si hacemos de esas pequeñas pistas de una mayor diversidad el centro de nuestra investigación? Esa fue la consigna con la que iniciamos nuestros trabajos en el ańo 2009, con el objetivo de comprender las historias ${ }^{3}$ de producción y transformaciones del arte rupestre de la sierra. Desde entonces, hemos aplicado distintas técnicas de análisis que han permitido vislumbrar algunos fragmentos de estos procesos. Sin embargo, más allá de las téc-

2 Los fechados obtenidos en La Candelaria se disponen entre el 700 y el 1300 DC. Estas dataciones constituyen las únicas fechas absolutas del arte rupestre de la sierra de El Alto-Ancasti hasta el momento.

3 Con el concepto de historia, a lo largo de este trabajo se hace referencia a los procesos mediante los cuales las personas elaboran y transforman el mundo y a sí mismas a lo largo del tiempo. En ese sentido, es el objetivo del artículo desarrollar una metodología científica que permita aproximarnos a la complejidad de dichos procesos vinculados a los abrigos con arte rupestre. De tal manera, en esta ocasión se excluyen del análisis las formas específicas mediante las cuales estos grupos conceptualizaron, construyeron y modificaron sus historias y memorias colectivas. nicas puntuales utilizadas, el carácter fragmentario del registro arqueológico, las características propias del arte rupestre de la zona (por ejemplo, el estado de conservación) y los interrogantes de investigación focalizados en las prácticas sociales, nos enfrentaron a la necesidad de aplicar una metodología que entrelace y articule retazos diferentes de las historias sucedidas en los sitios con arte rupestre. Dicha experiencia nos permitió comprender que la investigación de los procesos históricos desarrollados en estos sitios no debe ser considerada como un mero problema técnico -o, al menos, no solo eso-, sino que puede ser abordada mediante la aplicación de alternativas metodológicas que hagan uso de dichas técnicas de manera novedosa. Una metodología focalizada en una escala de las prácticas sociales que combina diferentes niveles de análisis y múltiples líneas de evidencias, fue el camino seleccionado para avanzar en dicho objetivo.

En las próximas páginas se describen los resultados obtenidos mediante la investigación de cinco líneas de evidencias diferentes: 1) Análisis espaciales; 2) Estudios de las superposiciones entre motivos; 3) Análisis morfológico-estilísticos; 4) Análisis químicos de las mezclas pigmentarias, y 5) Excavaciones estratigráficas de los depósitos sedimentarios presentes en los abrigos con arte rupestre. Como veremos, el abordaje de cada una de estas líneas involucró la selección de diferentes universos de análisis. En primer lugar, un nivel de paisaje para caracterizar espacialmente los diferentes sitios con arte rupestre de la sierra; luego adoptando un nivel de sitio para evaluar cómo dicha caracterización se tensiona al considerar la diversidad de abrigos en un solo sitio (Oyola). Posteriormente continuaremos con un nivel de sitio para explorar las superposiciones y las características morfológicas de las pinturas y grabados de Oyola; y por último, un nivel de abrigo para aproximarnos a las mezclas pigmentarias con que fueron elaboradas las pinturas de una de las cuevas de dicho sitio (Oyola 7) y revisar los resultados de las excavaciones estratigráficas allí realizadas. A diferencia de otros artículos en donde hemos realizado algunos de estos estudios con mayor profundidad, en esta ocasión deseamos concentrarnos en las posibilidades que resultan de su combinación y uso complementario. Por esta razón, y considerando la extensión que supone la descripción detallada de 
cada uno, en las próximas páginas se presenta una síntesis de los resultados alcanzados en cada línea, para exponer, luego, algunas de las conclusiones a las que hemos podido acceder a través de esta metodología.

\section{Los paisajes rupestres de El Alto-Ancasti}

A diferencia de otros materiales que estudia la arqueología, las pinturas y grabados rupestres se disponen en lugares relativamente similares a aquellos para los cuales fueron elaborados. Esta situación, que se desprende de la naturaleza inmueble y perdurable del arte rupestre, ha permitido el desarrollo de numerosas investigaciones que han intentado aproximarse a las antiguas pautas de selección de los espacios para ser pintados y/o grabados (Criado-Boado, 1993; Carden, 2008; Troncoso, 2008a; Martel, 2010). De esta forma, se han inferido algunos aspectos de las prácticas sociales ejecutadas en dichos lugares de acuerdo a las posibilidades de movimiento y acción que imponen, impulsan o habilitan, fundamentalmente a partir de la observación del arte rupestre como elemento estructurado y, a la vez, estructurante de tales prácticas.

En la investigación del arte rupestre de la sierra de El Alto-Ancasti, hemos seleccionado este tipo de análisis para comenzar a desentrañar la diversidad histórica y práctica de sus múltiples sitios. En primera instancia, dichos estudios fueron realizados en un nivel de análisis de paisaje que integra los distintos sitios arqueológicos con arte rupestre documentados hasta el momento en toda la sierra (Quesada y Gheco, 2011; Gheco, 2017). Mediante el registro y análisis de diferentes variables ${ }^{4}$ en cada uno, definimos cuatro modalidades o lógicas espaciales que agrupan a estos sitios y exponen posibilidades de acción diferentes estructuradas por el arte rupestre y su particular disposición (Figura 3).

4 Las variables analizadas fueron: visibilidad del abrigo, visualidad desde el abrigo, visión de los motivos desde el exterior de la cueva o alero, tamańo del abrigo, posibilidad de agregación de personas, ubicación topográfica del abrigo, proximidad con otros abrigos con arte y/o otros sitios arqueológicos, presencia de otros restos materiales en las cuevas.
En sitios como Oyola, La Tunita y Campo de las Piedras, por mencionar algunos ejemplos, los motivos rupestres -en su gran mayoría pintados- se ubican en el interior de grandes bloques de granito, conformando conjuntos de varias cuevas y aleros con arte rupestre relativamente próximos. Sin embargo, no todos los abrigos disponibles fueron seleccionados para realizar las pinturas, sino que, al parecer, fueron elegidos aquellos que reúnen algunas características: cuevas más bien pequeñas, donde pueden permanecer entre tres y seis personas simultáneamente; alejadas de los cursos de agua, de los espacios de producción agrícola y de vivienda; con escasa visibilidad desde el exterior, ya sea por el tamaño reducido de los accesos como también por la presencia de otras rocas cercanas (Figura 3A). Esta modalidad, que definimos como " 1 ", se contrapone con otra lógica espacial que creemos haber detectado en sitios como La Candelaria, Inasillo o Casa Pintada de Guayamba. En este caso, la modalidad " 2 " está definida por un único abrigo en cada sitio, de grandes dimensiones y próximo a ríos o arroyos. Los motivos rupestres de estos abrigos, en su totalidad pintados, pueden ser apreciados desde el exterior de las cuevas y aleros, especialmente desde los sectores aterrazados a través de potentes muros de rocas construidos justo por fuera de la línea de goteo (Figura 3B).

Una tercera lógica espacial -Modalidad “ 3 ”- fue identificada en sitios como Puesto La Mesada y Pisada del Avestruz. A diferencia de los demás, en este caso se trata de grabados profundos ejecutados sobre la cara superior de grandes rocas horizontales asociadas a los antiguos campos de cultivo y espacios residenciales. Estas rocas son visibles a gran distancia dependiendo de las características de la vegetación, aunque los motivos propiamente dichos solo pueden ser apreciados al situarse justo por encima de ellos o a escasos metros (Figura 3C). Finalmente, una última modalidad, "4", fue propuesta para un conjunto de sitios como Ampolla, El Mojón y Casa del Gallo, caracterizados por presentar pinturas rupestres que se ubican en peñascos rocosos y pequeños aleros dispuestos en los márgenes de ríos, cascadas o espejos de agua. En estos casos, la permanencia en los espacios próximos a las pinturas es dificultosa por lo escarpado del terreno y, por el contrario, parece haberse privilegiado la observación 


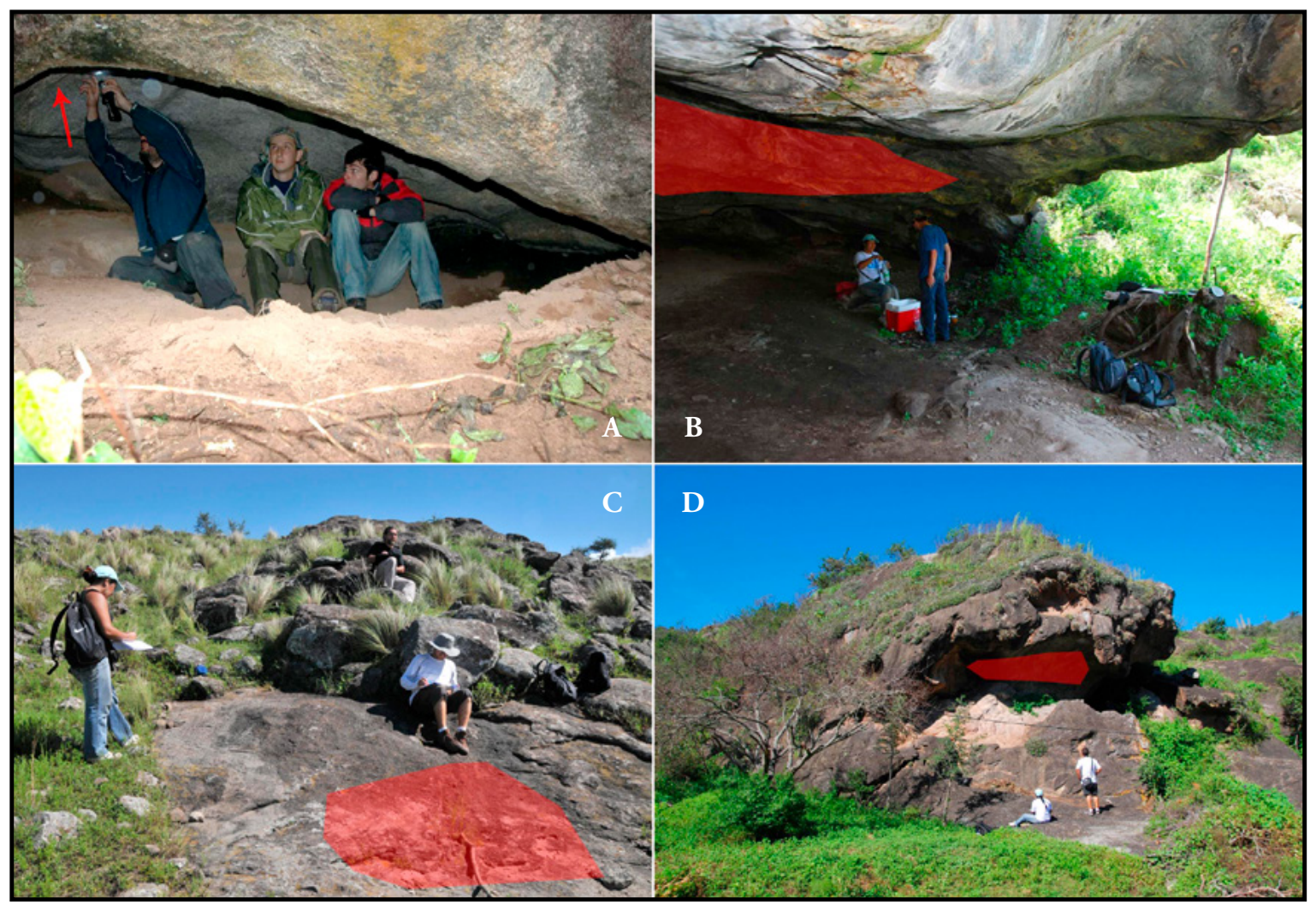

Figura 3. Modalidades espaciales de los sitios con arte rupestre de la sierra de El Alto-Ancasti. Las flechas y zonas rojas indican los sectores con pinturas/grabados.

algo distante de los motivos, a unos 5 o 10 metros, desde las orillas de los cursos de agua (Figura 3D).

Si bien no es el objetivo del artículo exponer en detalle los resultados de estos estudios, los comentarios anteriores permiten apreciar que incluso en un nivel de análisis general que considera todos los sitios con arte rupestre de la sierra, es factible identificar una pluralidad de lógicas espaciales asociadas al arte rupestre que promueven acciones, movimientos y desplazamientos bastante diferentes. En este sentido, si recordamos que el arte rupestre es un producto y, a la vez, un elemento estructurante de las prácticas sociales realizadas a su alrededor, podemos suponer una diversidad semejante de tales prácticas emprendidas en estos espacios. Reuniones íntimas en espacios reducidos y oscuros (Modalidad 1); congregaciones numerosas de personas, quizás acompañadas de danzas (Modalidad 2); grabados asociados a los espacios agrícolas y de vivienda (Modalidad 3), y pinturas visibles al desplazarse por los márgenes de ríos y cascadas (Modalidad 4) podrían ser algunos ejemplos de la multiplicidad de usos posibles de los abrigos con arte rupestre de la zona.

Sin embargo este nivel de análisis posee algunos inconvenientes. Entre estos, si bien nos permite advertir algunos aspectos de la heterogeneidad del arte rupestre de la sierra, la definición de las modalidades eclipsa detrás de una misma lógica espacial, definida para caracterizar un conjunto de sitios, una diversidad mayor cuyos indicios se revelan cuando modificamos el nivel de análisis y nos centramos, por ejemplo, en las distintas cuevas que constituyen algunos de ellos. Con ese objetivo abordamos el estudio exhaustivo de los múltiples abrigos de Oyola, uno de los tantos sitios con arte rupestre de El Alto-Ancasti, cuya elección respondió al elevado número de cuevas y aleros identificados, a la heterogeneidad de las figuras pintadas, al buen estado de conservación y a la posibilidad de realizar excavaciones estratigráficas en algunas cuevas, entre otros aspectos. 


\section{Los paisajes rupestres de Oyola}

El sitio de Oyola comenzó a ser estudiado a mediados del siglo XX, con los trabajos pioneros de Gramajo y Martínez Moreno (1978), quienes documentaron siete abrigos con arte rupestre y los vincularon a la Cultura La Aguada. Posteriormente, otros artículos retomaron algunas de las pinturas rupestres descriptas como ejemplos del accionar de dicha entidad cultural (Gordillo et al., 2000). A partir del año 2009, desde el Equipo Interdisciplinario El AltoAncasti iniciamos los trabajos en la zona, alternando nuevas prospecciones, excavaciones estratigráficas y detalladas documentaciones del arte rupestre. Las últimas prospecciones en Oyola permitieron identificar 38 abrigos y bloques rocosos con arte rupestre dispersos en la densa vegetación que recubre las lomadas de un batolito o plutón de granito, además de numerosas estructuras habitacionales y agrícolas
(Quesada, Zuccarelli, Gheco, Gastaldi y Boscatto, 2016).

En los últimos años, el relevamiento de las diferentes variables espaciales mencionadas párrafos atrás pero, en este caso, considerando solo los abrigos de Oyola, suscitó que aquellas aparentes excepciones en los paisajes rupestres de toda la sierra se releven como datos significativos y recurrentes al centrar la mirada en un solo sitio. De este modo, la clasificación de todo Oyola dentro de una modalidad espacial caracterizada por pequeñas cuevas con pinturas (Modalidad 1) se disgregó en cuatro lógicas espaciales distintas que pueden ser identificadas en estos abrigos: grandes cuevas con pinturas rupestres (Modalidad B - Figura 4B); bloques rocosos con grabados asociados a los espacios agrícolas y residenciales (Modalidad D - Figura 4D); aleros con pinturas rupestres visibles a la distancia (Modalidad

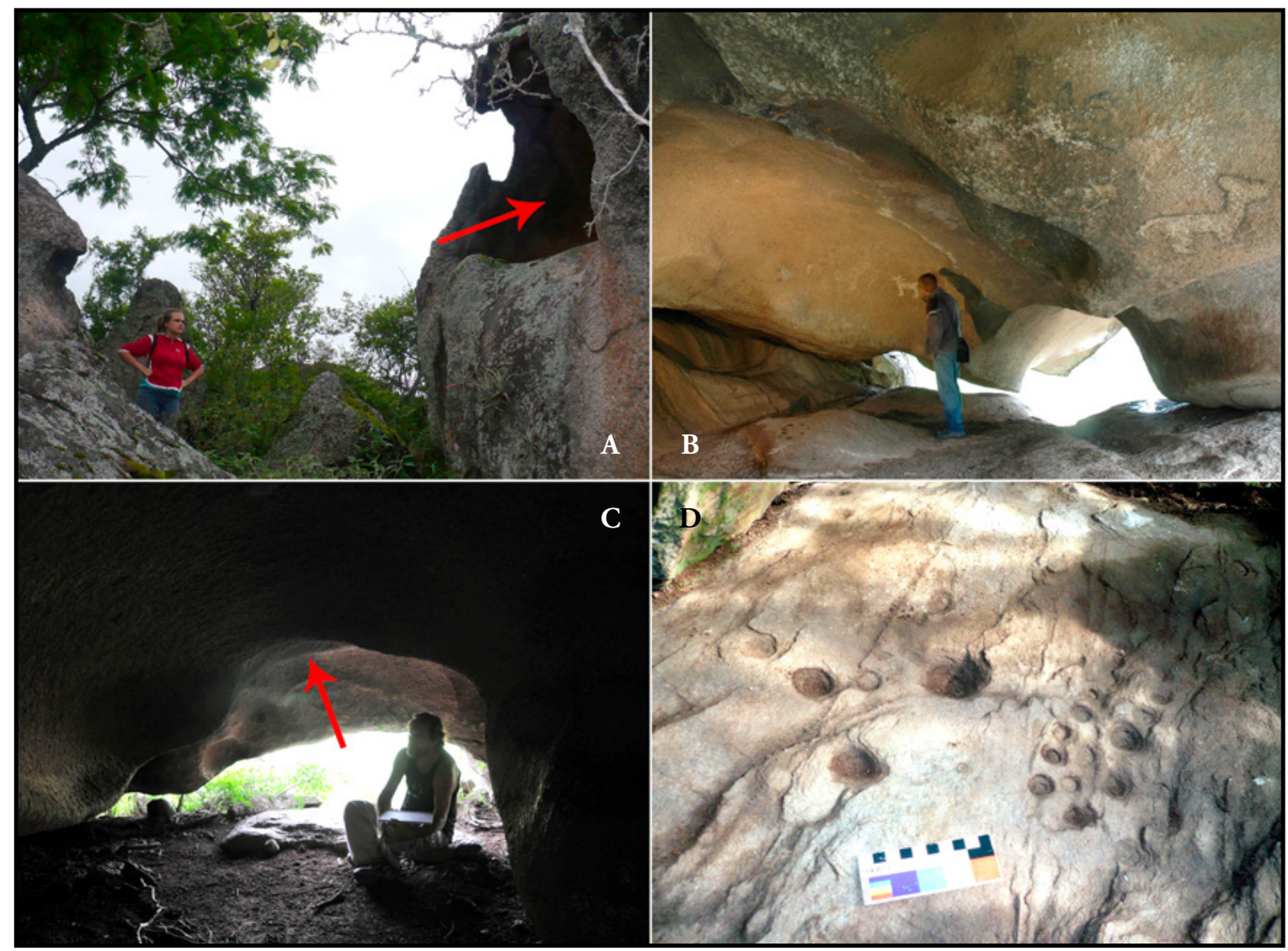

Figura 4. Modalidades espaciales de los abrigos con arte rupestre de Oyola. Las flechas indican los sectores con pinturas/grabados. 
A - Figura 4A), y las mencionadas pequeñas cuevas con pinturas (Modalidad C - Figura 4C) (Gheco, 2017). Por lo tanto, al modificar el nivel de análisis $y$, de esta manera, transformarse las relaciones entre las tendencias generales y los casos particulares, fue posible detectar una diversidad mayor en la disposición espacial del arte rupestre del sitio.

Sin embargo, aunque la modificación del nivel de análisis resulte significativa para advertir estas diferencias al interior de un sitio como Oyola, la definición de las modalidades espaciales aún posee varios inconvenientes. Cada una de ellas representa un modelo resumido y simplificado que crea una sincronía al sintetizar en un plano procesos más largos y complejos integrados por diversas prácticas sociales acaecidas en cada una de las cuevas a lo largo del tiempo. Así, este enfoque presenta como constante y homogéneo lo que es producto de una historia de agregados y transformaciones. Pero, entonces, ¿cómo salvar estos inconvenientes y avanzar en el conocimiento de estos procesos históricos? Creemos que es posible mediante la combinación de los datos espaciales con otras líneas de evidencias que informen sobre la diacronía de dichos procesos, sobre sus particularidades, sus ritmos y tiempos.

\section{Historias superpuestas}

Al iniciar la sección anterior mencionamos dos características fundamentales del arte rupestre: su perdurabilidad e inmovilidad. Como producto de ambos factores se desprende lo que Aschero (1996, 1994) denominó como el carácter aditivo del arte rupestre, es decir, la capacidad de crear verdaderos montajes policrónicos como resultado de la incorporación de nuevas figuras en los mismos paneles a lo largo del tiempo (Didi-Huberman, 2008, 2009; Quesada y Gheco, 2015). Entre las diferentes estrategias para estudiar estos procesos, el análisis de las superposiciones entre motivos ha sido empleado como una de las herramientas fundamentales, ya sea a partir de su uso como indicador cronológico para el establecimiento de secuencias relativas de los eventos de confección, como también como elemento para aproximarse a las estrategias y actitudes de quienes confeccionaron los nuevos motivos con respecto a los que ya estaban en las paredes o techos (Loubser, 1984; Aschero, 1988; Russell, 2000;
Rogerio Candelera, 2014; Re, 2016; Gheco, 2017). Ambos usos de las superposiciones vuelven necesarios estudios detallados cuya factibilidad se vincula a la elección de un nivel de análisis acorde a las posibilidades de investigación. Por ello, seleccionamos los abrigos de Oyola para desarrollar estos trabajos, con la esperanza de que la comprensión en detalle de este sitio sirva para ilustrar cómo podrían haber sido los procesos desarrollados en los demás.

En cada una de las cuevas, aleros y bloques rocosos de Oyola fueron documentadas las superposiciones de acuerdo a dos variables: el alcance del solapamiento y las características tonales de los motivos en contacto. ${ }^{5}$ En total fueron detectadas 24 superposiciones en los 38 abrigos del sitio, incluyendo los casos en los que intervienen motivos modernos (por ejemplo, inscripciones en aerosol). En otros artículos hemos descripto con mayor detalle cada uno de estos eventos de superposiciones (Gheco y Quesada, 2012; Quesada y Gheco, 2015; Gheco, 2017). En esta ocasión, en cambio, deseamos centrarnos en algunas de las conclusiones que se desprenden de estos estudios.

En primer lugar, si consideramos el elevado número de abrigos y de motivos rupestres en el sitio, resalta la escasez de superposiciones relevadas, solo 24 en 38 cuevas/aleros con más de 300 motivos documentados. Sin embargo, a pesar del pequeño número, estas nos informan de la diacronía en la confección de las pinturas de las cuevas, aunque no conocemos

5 1) Alcance de la superposición: se refiere al área de contacto o solapamiento entre las figuras.

- Mínimo: menor a $0,5 \mathrm{~cm}$ o al $10 \%$ del tamaño total de las figuras en contacto.

- Parcial: mayor a $0,5 \mathrm{~cm}$ y entre el $10 \%$ y $50 \%$ del tamańo de las figuras en contacto.

- Total: mayor al 50\% del tamańo de las figuras en contacto.

2) Características tonales: esta variable implica la apreciación de las similitudes y diferencias cromáticas entre las figuras superpuestas y cómo estos colores inciden en la detección de las superposiciones:

- Tonalidad similar: cuando los colores de las figuras superpuestas son cromáticamente muy próximos, a tal punto de dificultar la distinción entre uno y otro motivo. - Tonalidad contrastante: cuando los colores de las figuras superpuestas son diferentes y generan condiciones de contraste que posibilitan su rápida discriminación. 
la distancia temporal entre los eventos. Igualmente, el análisis se vuelve más interesante si indagamos en las características específicas de estas superposiciones $\mathrm{y}$, de tal modo, intentamos acercarnos a las formas de vinculación espacial entre las figuras correspondientes a los distintos eventos de pintado.

En siete casos de las 24 superposiciones relevadas intervienen escritos y pinturas modernas. En estos casos se repiten características similares: superposiciones de alcance total o parcial y entre figuras de tonalidades contrastantes (Figura 5A). Es decir, se trata de motivos dispuestos directamente por encima de las figuras más antiguas y confeccionados con colores diferentes de aquellas. En cambio, cuando analizamos solo los casos en donde se contactan motivos prehispánicos, la situación es totalmente inversa. En 15 de las restantes 17 superposiciones los motivos se solapan solo unos pocos milímetros y presentan colores similares entre sí, haciendo muy difícil la detección de la superposición en cuestión. Solo dos casos en todo el sitio presentan motivos rupestres de tonalidades contrastantes y superpuestos en mayor medida (Figura 5B).

La escasez de superposiciones en Oyola, sumada a los problemas que supone la observación de la gran mayoría de los casos en donde intervienen solo los motivos prehispánicos, nos enfrenta a frisos rupestres que se transformaron en el tiempo pero en los cuales resultan muy difíciles de detectar los indicios de los cambios y agregados. Esta conclusión, incluso, puede resultar más evidente si comparamos los paneles de Oyola con los documentados en otros sitios arqueológicos bien conocidos en la región andina como los de Confluencia, en la puna argentina, y Taira, en Chile (Berenguer, 2004; Martel, Rodríguez Curletto y Del Bel, 2012). En ellos se presentan lógicas de agregación de motivos totalmente diferentes, donde la superposición entre las figuras parece haber sido la regla antes que la excepción. Frente a estos paneles, resultan ilustrativas las palabras de uno de sus investigadores:

Continuamente grabados y vueltos a grabar, pintados y repintados, los paneles de este estilo [Taira] dan la sensación de obras en constante ejecución, jamás concluidas [...]. En otras palabras, pareciera que los sitios con este arte rupestre hubieran sido periódicamente revisitados y sus paneles intermitentemente intervenidos y, quizás, renovados (Berenguer, 2004, p. 85).

Por el contrario, las escasas superposiciones en Oyola y sus particulares características de solapamientos diminutos y similitudes cromáticas entre las figuras parecen situarnos ante experiencias totalmente opuestas en las que prima la quietud y la uniformidad. Paredes de apariencia inalterada, aunque las mismas superposiciones y, como veremos, otras líneas de evidencias, nos informan de sus constantes transformaciones.

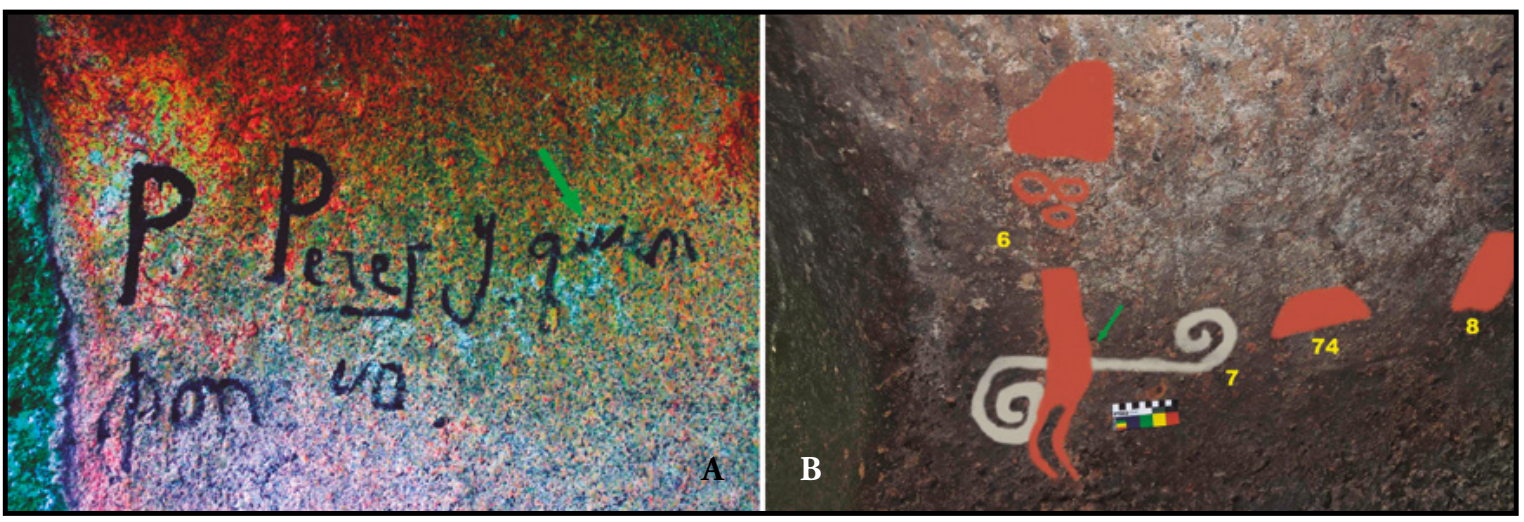

Figura 5. Ejemplos de superposiciones relevadas en el sitio de Oyola.

A. inscripciones modernas en color negro sobre motivos grabados de camélidos. B. Figura roja de características antropomorfas superpuesta a un diseńo lineal de extremos en espiral pintado en color blanco. 


\section{Los estilos de Oyola}

Las primeras dos líneas de evidencias que repasamos resultaron herramientas útiles para comenzar a desarmar la apariencia homogénea del arte rupestre de la sierra de El Alto-Ancasti. Como vimos, con los estudios espaciales pudimos detectar diferentes pautas de selección de los abrigos para ser pintados/grabados. Así, ya sea considerando los distintos sitios de la sierra como también analizando los diferentes abrigos de algunos de ellos, pudimos entrever la posible existencia de una diversidad similar de prácticas sociales que dieron forma, utilizaron y fueron estructuradas por las propias imágenes rupestres. Los análisis de las superposiciones, por su parte, nos permitieron advertir que algunos de estos sitios -puntualmente el de Oyola- son el producto de varios eventos de confección y agregados de motivos. Pero, además de confirmarse esta diacronía, las superposiciones también nos enfrentaron a formas puntuales de vinculación entre los distintos eventos de pintado prehispánicos, en las cuales se evitaron los contactos entre figuras, o bien se los hizo poco evidentes.

Sin embargo, aún son necesarios mayores datos para comprender la complejidad de las historias de construcción de los paneles rupestres. Para ello decidimos explorar otra técnica de análisis cuya aplicación a los estudios del arte rupestre es relativamente frecuente, pero sus posibilidades pueden multiplicarse mediante su interconexión con otras líneas de evidencias complementarias: los estudios morfológicoestilísticos.

El análisis estilístico ha sido una de las formas privilegiadas para abordar la investigación de las imágenes prehispánicas independientemente del material sobre el cual han sido realizadas (Gordillo, 2009; Basile, 2011; Kligmann y Falchi, 2018). Esta herramienta, más allá de los marcos teóricos que guiaron su interpretación, ha sido empleada para separar y secuenciar, es decir, como una forma de establecer modos de hacer figuras relativamente similares, en ocasiones posibles de ser ordenadas en términos cronológicos. Existe una variada bibliografía con revisiones muy interesantes sobre la aplicación del concepto de estilo en arqueología y, en particular, en los estudios del arte rupestre del Noroeste Argentino (Llamazares y Slavutsky, 1990; Runcio, 2007;
Basile, 2011). En esta ocasión, con el concepto de estilos nos referimos al resultado de un proceso de negociación práctica de las personas ante las rocas, procesos en los que se intersectan diversos planos (que involucran lo aprendido, lo que se quiere hacer, lo que ya está hecho y lo que se quiere dejar, entre otros) cuyos resultados pintados o grabados exhiben grandes similitudes formales, posibles de ser interpretadas como parte de cierta cronología común -lo que nos impulsa a usar tentativamente el estilo como herramienta para secuenciar- pero que también pueden involucrar tiempos distintos, incluso contradictorios. Esta noción del estilo intenta apartarse de cualquier determinismo normativo y se aproxima a la concepción de Hodder (1990) del estilo como un modo de hacer, en el que cada figura expresa la referencia del evento individual a una manera general de hacer pero, al mismo tiempo, transforma el contexto que van a retomar las futuras acciones. Este concepto también advierte de la complejidad policrónica del estilo, que trasciende la visión tradicional, lineal y sucesiva de compartimentos estilísticos como totalidades cerradas, y nos obliga a adoptar una perspectiva más plástica e inestable atenta a los contratiempos y a las supervivencias (Didi-Huberman, 2008, 2009). Por último, esta noción del estilo como modo de hacer, y no como un modo de representar, pretende focalizarse en la praxis involucrada en la ejecución de las figuras y en el carácter activo de las personas antes que asumir que dichos motivos son la representación de una realidad externa a ellos, noción ampliamente criticada desde la antropología del arte por su ausencia en muchos pueblos por fuera del occidente moderno (Lagrou, 2010).

Para profundizar y complementar los datos brindados por las líneas de evidencias expuestas, también elegimos los abrigos de Oyola para realizar el estudio estilístico de sus pinturas. ${ }^{6}$ Entre los distintos resultados obtenidos, es importante a los fines de este artículo centrarnos en el análisis de los motivos

6 Para los estudios estilísticos fueron consideradas las características morfológicas y cromáticas de las figuras, el tratamiento plástico de las imágenes (lineal, plano, plano delineado, etc.) y la técnica de confección. Para mayores detalles sobre estos estudios en Oyola, ver Gheco (2017). 


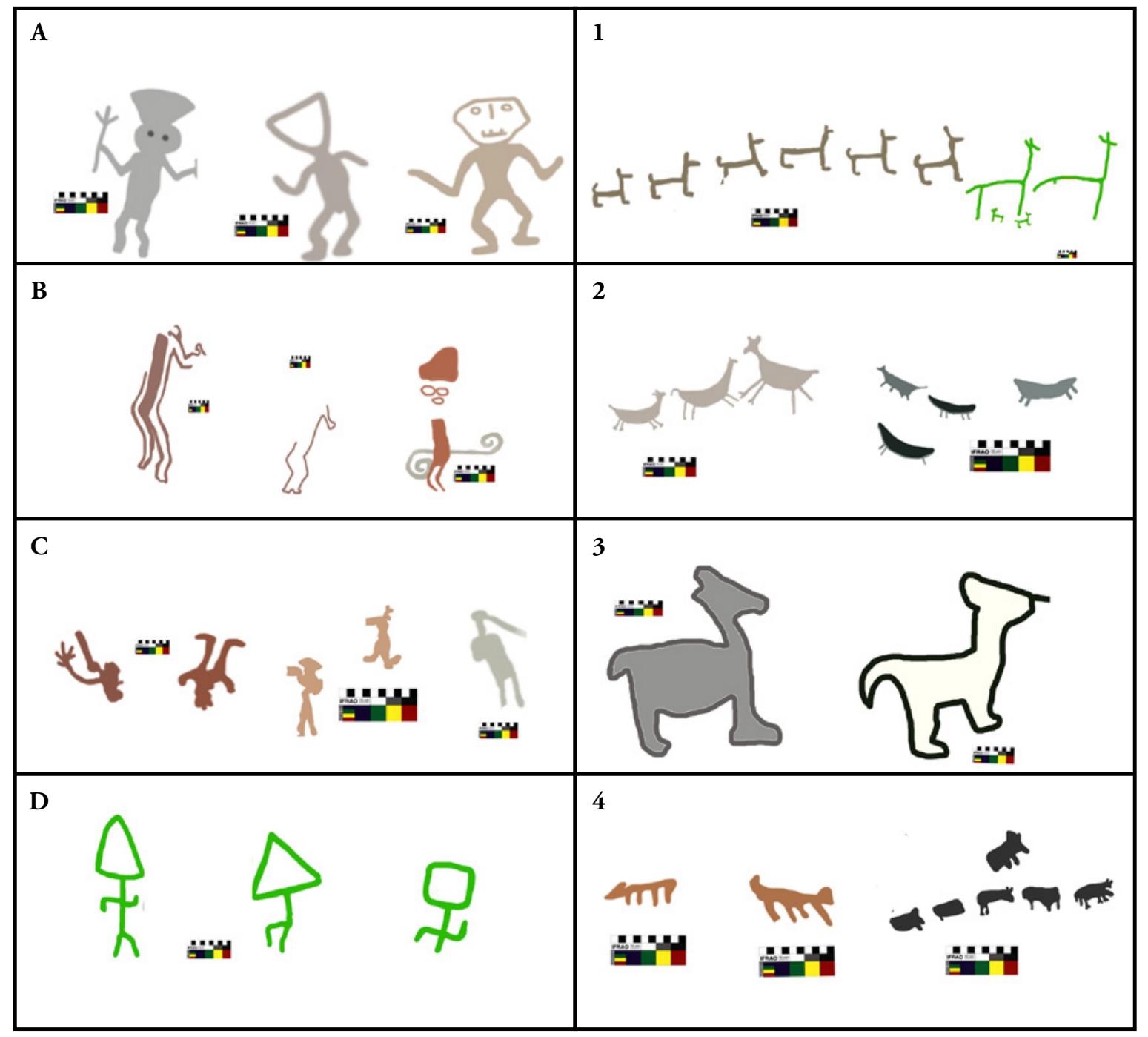

Figura 6. Modalidades estilísticas de las figuras de antropomorfos y camélidos del sitio de Oyola. Los colores expuestos representan las características cromáticas de las figuras, salvo el color verde que indica los motivos grabados.

figurativos más frecuentes en el sitio: los camélidos ${ }^{7}$ $(n=209)$ y los antropomorfos $(n=34)$. Cada uno de estos motivos fue documentado en detalle $y$, a partir del relevamiento de sus características formales, clasificado en modalidades estilísticas distintas que expresan modos de hacer diferentes y recurrentes de estas figuras. Para cada caso fueron definidas cuatro modalidades, ${ }^{8}$ cuyas características y relativa diver-

7 En algunos casos sería mejor denominar a este grupo como "cuadrúpedos" dado que, en ocasiones, resulta dificultoso definir si se trata de camélidos o de otros animales como cérvidos o equinos, por ejemplo.

8 Utilizamos la noción de modalidad para apartarnos de conceptos más normativos como el de canon o patrón. sidad interna pueden ser apreciadas en la Figura 6. De este estudio se desprenden, cuanto menos, tres conclusiones importantes.

La primera de ellas se vincula con la diversidad de figuras de camélidos y antropomorfos relevadas en el sitio y sus posibles diferentes cronologías. En este sentido, se vuelven significativas las asociaciones recurrentes observadas entre algunas de estas modalidades y otros motivos del sitio, factibles de ser conectadas, a su vez, con las clasificaciones y cronologías elaboradas por diferentes autores para regiones próximas a $\mathrm{El}$ Alto-Ancasti. Por ejemplo, fue posible advertir la asociación entre los antropomorfos de la Modalidad A 
y los camélidos de la Modalidad 3, ambos conjuntos similares a los descriptos para el Período Medio o la Cultura La Aguada en la puna argentina (Figura 7A) (Aschero, 2000). La presencia en los mismos abrigos y con técnicas, colores y tratamientos plásticos similares de motivos de felinos morfológicamente análogos a los descriptos para este momento/cultura podría ser otro elemento que apoye dichas asociaciones y cronologías (González, 1998; Gordillo et al., 2000; Kusch, Hoffmann y Abal, 2000). De igual forma, observamos la presencia reiterada de camélidos incluidos dentro de la Modalidad 2 con antropomorfos de la Modalidad C (Figura 7B). En este caso, las clasificaciones disponibles para el Noroeste Argentino presentan motivos similares para momentos tempranos en el desarrollo cultural de la región, quizás miles de ańos antes del Período Agroalfarero (Aschero, 2006). Por último, algunas modalidades presentan mayores dificultades para su atribución cronológica, por ejemplo la Modalidad 1 de camélidos, asignada a los períodos Tardío e Inka en el norte de Chile (Aschero, 2000; Sepúlveda, 2004; Troncoso, 2012) pero también posible de ser vinculada al Formativo a partir de las clasificaciones del arte rupestre de los valles Calchaquíes (Ledesma, 2012).

La segunda conclusión obtenida de los estudios estilísticos en Oyola se refiere a la frecuencia de estas modalidades al interior de los abrigos del sitio. Cuando nos desplazamos de un nivel de análisis de sitio hacia cada una de las cuevas o aleros, notamos que aquella diversidad de motivos de camélidos y antropomorfos es reemplazada por una mayor homogeneidad. El 62\% de los abrigos en donde fueron documentados camélidos presentan figuras asignadas a una única modalidad estilística, situación que asciende al 87\% de los abrigos si consideramos una tolerancia de dos figuras de camélidos diferentes en el mismo alero/cueva. De manera similar, en el 83\% de los abrigos en donde hemos documentado figuras antropomorfas, estas pueden adscribirse a una única modalidad (Figura 8).

Por último, si consideramos que aún las figuras de una misma modalidad al interior de cada abrigo habrían sido realizadas en varios eventos de pintado, como nos lo informan las superposiciones y, como veremos, también los análisis químicos, nos enfrentamos a una tercera conclusión: una y otra vez, quienes pintaron los abrigos de Oyola agregaron nuevas figuras de camélidos y antropomorfos con formas relativamente similares e, incluso, con tonalidades muy próximas a las que ya estaban en los mismos paneles. De esta manera, los análisis estilísticos, al igual que los estudios de las superposiciones, nos conducen a entrever lo que parecen haber sido lógicas de agregación de motivos en el tiempo que conformaron repertorios relativamente uniformes y en donde los cambios resultan poco evidentes.
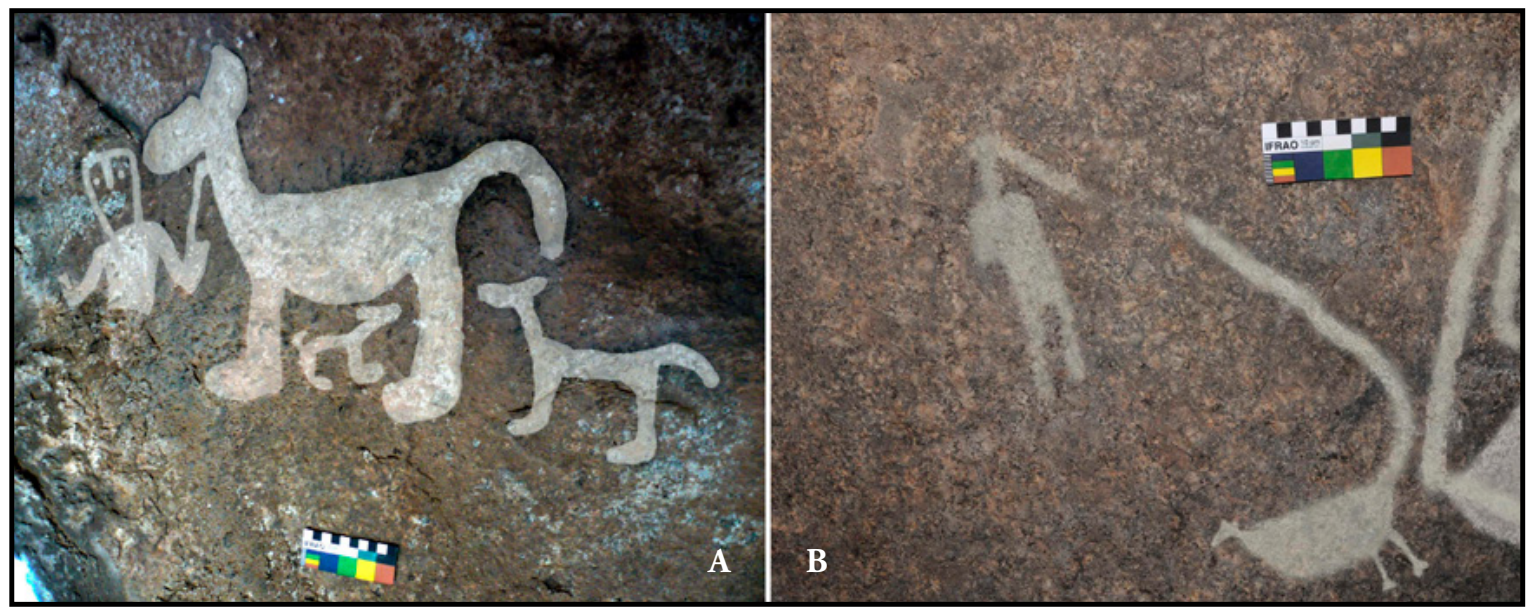

Figura 7. Asociaciones recurrentes detectadas entre modalidades estilísticas de camélidos y antropomorfos en Oyola. 


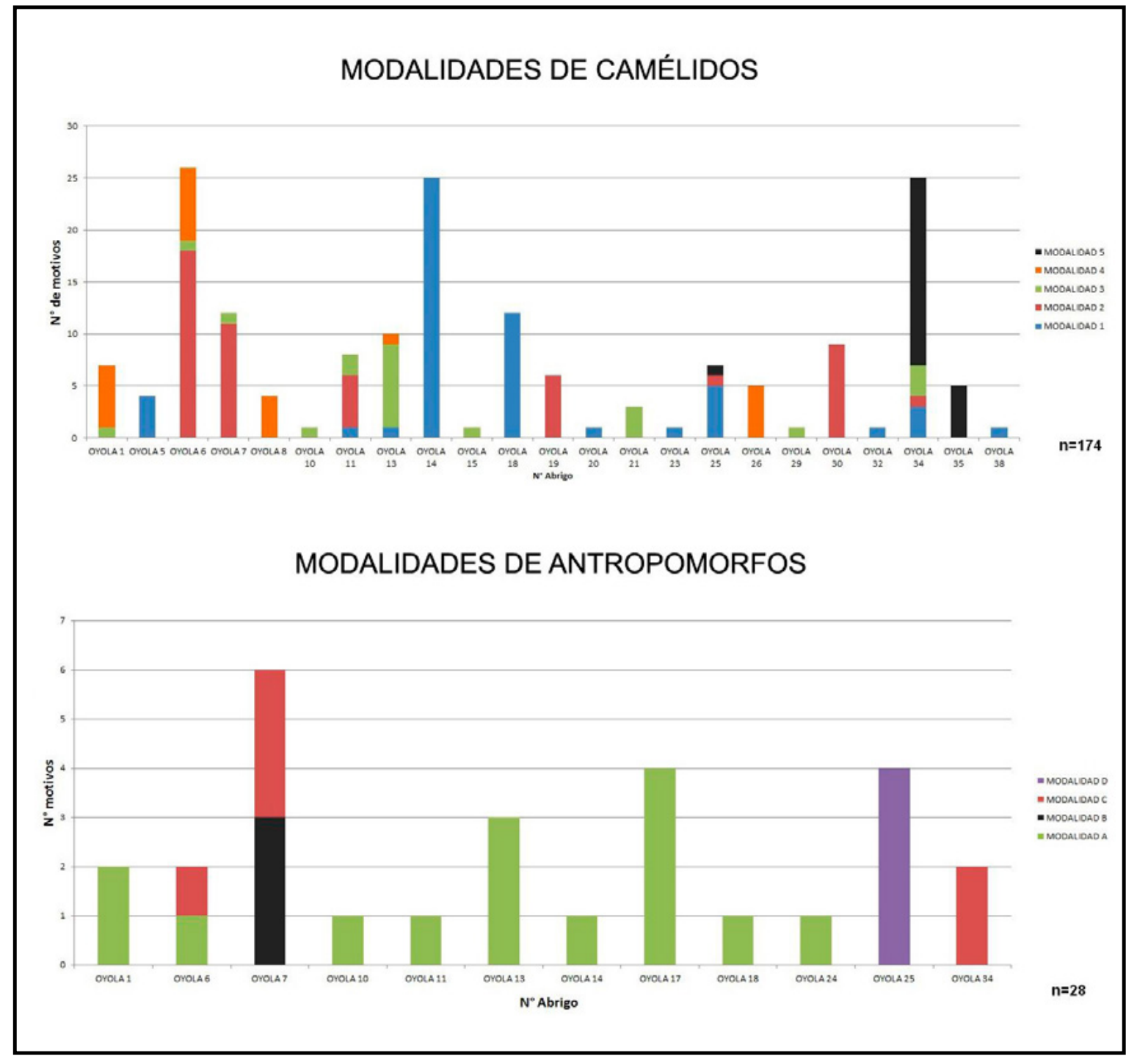

Figura 8. Frecuencia de las modalidades de camélidos y antropomorfos en los abrigos de Oyola.

\section{Historias en la tierra}

Una de las líneas de evidencias más importante a la hora de comprender las prácticas sociales desarrolladas en los abrigos con arte rupestre es la excavación de los depósitos sedimentarios ubicados en su interior. En particular, la excavación estratigráfica posee un especial potencial a la hora de investigar las actividades concretas desarrolladas en estos espacios, ya que permite desentrañar los eventos específicos (antrópicos y naturales) que les dieron forma y los modificaron en el tiempo (Harris, 1991; Carandini, 1997).
Entre los abrigos con arte rupestre de Oyola, seleccionamos la cueva Oyola 7 para realizar la excavación de casi la totalidad del área disponible $\left(35 \mathrm{~m}^{2}\right.$ aprox.) siguiendo los principios de estratigrafía definidos por E. Harris (1991). De este modo, nos desplazamos desde un nivel de análisis de sitio a uno de abrigo para desarrollar estas actividades y garantizar su factibilidad. Hasta el momento fueron realizadas cuatro temporadas de excavaciones entre los ańos 2014-2017, en las cuales se definieron 139 unidades estratigráficas cuya relación temporal puede ser apreciada en la matriz expuesta en la Figura 9. En otros trabajos hemos descripto con mayor detalle los 


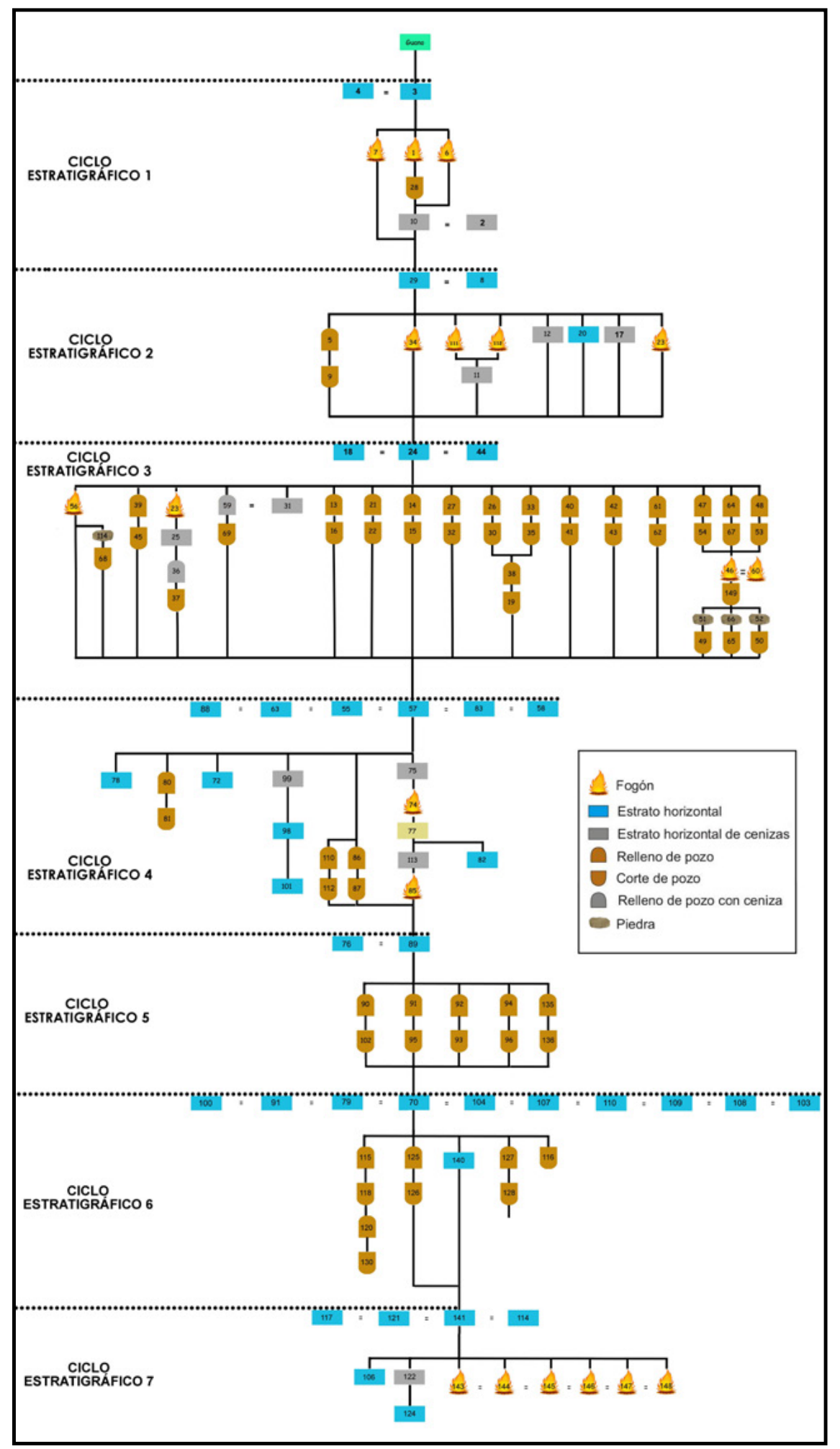

Figura 9. Matriz estratigráfica de la excavación de Oyola 7. Cada símbolo representa una unidad estratigráfica (estratos horizontales, pozos, rellenos de pozos y fogones). Los estratos ubicados en el sector superior de la matriz son más recientes, por lo tanto, el Ciclo Estratigráfico 7 contiene los eventos estratigráficos más antiguos detectados. 
avances alcanzados en el análisis de los materiales recuperados (cerámicas, líticos, óseos, pigmentos y metales) así como las interpretaciones de la secuencia estratigráfica (Gastaldi et al., 2016; Gheco, 2017; Gheco et al., 2017; Gheco, Gastaldi, et al., 2019). En esta ocasión, al igual que en las secciones previas, nos concentraremos en algunas de las conclusiones de esos estudios que resultan de importancia para la discusión de este artículo.

Las características de los estratos identificados en Oyola 7, junto a las relaciones estratigráficas advertidas entre ellos, nos permitieron definir -hasta el momento- un número mínimo de siete ciclos estratigráficos (sensu Carandini, 1997) que interpretamos como siete momentos de mayor intensidad en el uso del abrigo, separados por períodos de menor transformación estratigráfica y, por tanto, de una menor intensidad en las actividades realizadas. Esta situación nos habilita a pensar en sucesivas ocupaciones de la cueva a lo largo de un período temporal cuya duración, en parte, desconocemos. En la actualidad contamos con dos dataciones absolutas de los carbones hallados en el tercer ciclo estratigráfico, ambas próximas al 800 DC (1260 \pm 90 [LP 3183 $\delta^{13} \mathrm{C}:-24 \pm 2 \%$ ] y $1230 \pm 70 \mathrm{AP}\left[\mathrm{LP} 3181-\delta^{13} \mathrm{C}\right.$ : $-24 \pm 2 \%$ ]). Dado que este ciclo se dispone en el sector medio de la secuencia estratigráfica, debemos considerar que necesariamente existieron ocupaciones más recientes y otras de mayor antigüedad, aunque no conocemos la distancia cronológica entre los eventos. ${ }^{9}$

Por otra parte, resulta interesante mencionar algunos aspectos de las actividades inferidas a partir de los materiales recuperados. Entre las múltiples prácticas sociales documentadas, existen algunas que se destacan por su recurrencia e interconexión con la mayoría de los materiales localizados. Se trata de la ejecución de pequeños fogones, encendidos contra las paredes internas de la cueva, variando su localización en cada ciclo, pero manteniendo un tamaño relativamente similar. Algunos fragmentos cerámicos y restos óseos de camélidos que fueron localizados en estos estratos presentan rastros de carbonización,

9 Se encuentran en ejecución nuevos fechados radiocarbónicos que permitirán ajustar la cronología de la matriz estratigráfica. por lo cual suponemos que habrían participado de esas actividades.

Del mismo modo, a lo largo de la historia de ocupaciones del abrigo, hemos documentado las evidencias de las últimas etapas en la producción de instrumentos líticos en cuarzo, como puntas de proyectil, raspadores, raederas y cortantes en general (Egea, 2015; Gastaldi et al., 2016). En cuanto a los restos cerámicos, se destaca la casi total ausencia de cerámica pintada o grabada, representando solo un $8 \%(\mathrm{n}=23)$ de los fragmentos hallados en la cueva $(\mathrm{n}=270)$. Estos valores, al igual que las características de las cerámicas estudiadas, se mantienen relativamente constantes a lo largo de la estratigrafía. Los restos óseos, por su parte, están dominados por el taxón Camelidae en toda la matriz, aunque la alta meteorización y el carácter fragmentario de estos vestigios impiden determinar las especies en particular o, por ejemplo, la existencia de huellas de cortes.

Si comparamos estos hallazgos con los realizados en otros sitios cercanos, podemos advertir que el tamaño y las formas de los fogones, las características de los desechos de talla y las frecuencias de los restos óseos y cerámicos presentan notables diferencias con los localizados en las estructuras habitacionales de uso relativamente permanente que excavamos en Oyola (Oyola 31 y Oyola 51) y en El Taco 19, otro sitio próximo en la cumbre de la sierra (Moreno y Quesada, 2012; Quesada, Gastaldi y Granizo, 2012; Ahumada, 2016; Ahumada y Moreno, 2016; Barot, 2017). Al contrario que en esas antiguas casas, los materiales recuperados en Oyola 7 nos inducen a pensar que esta cueva fue ocupada reiteradamente para realizar actividades esporádicas y de corta duración; actividades que, según los datos estratigráficos y los obtenidos del análisis de los materiales, habrían presentado notables similitudes entre sí a lo largo del tiempo, como si en cada momento de ocupación las prácticas sociales ejecutadas hubieran reproducido, aunque con pequeńas variaciones, lo realizado en momentos anteriores.

\section{Historias diminutas}

La quinta y última línea de evidencias explorada se vincula con el análisis químico de pequeñas muestras extraídas de las pinturas y soportes rupestres. Como 
mencionamos al inicio del trabajo, en las últimas décadas los estudios físico-químicos han representado una de las formas privilegiadas para estudiar el arte rupestre, aportando valiosos datos sobre los componentes utilizados en la producción de las pinturas, sobre las técnicas empleadas en la confección de los grabados, de las transformaciones diagenéticas desarrolladas por estos materiales en el tiempo $\mathrm{e}$, incluso, permitiendo las dataciones absolutas de las figuras (Russ, Hyman y Rowe, 1992; Edwards, Russell y Seaward, 1997; Bednarik, 2002; Jones, 2004; Yacobaccio, Cata, Sola y Alonso, 2008; Fiore, 2009; Sepúlveda, 2011; Bonneau, Pearce y Pollard, 2012; Ruiz et al., 2012; López et al., 2013; Troncoso, Moya, Sepúlveda y Carcamo, 2015). En algunas ocasiones, dichos estudios han servido para la elaboración de las cadenas operativas y las recetas pictóricas utilizadas en la producción del arte rupestre de grandes áreas o regiones a partir de las similitudes físicas y/o químicas detectadas entre pinturas de los mismos colores localizadas en diferentes cuevas y sitios, en ocasiones bastante apartados entre sí. Aunque es innegable el gran avance que suponen estos estudios para el conocimiento del arte rupestre, creemos que es posible complementarlos y potenciar sus posibilidades si situamos el foco de atención en las diferencias que presentan las mezclas pigmentarias relevadas en cada sitio y hasta en los mismos paneles.

Desde hace un tiempo que indagamos en las distintas técnicas y métodos para advertir las pistas de una mayor heterogeneidad en las pinturas de colores similares localizadas en los abrigos de un sitio o dentro de una misma cueva (Gheco, Quesada, Ybarra, Poliszuk y Burgos, 2013). Esta estrategia de investigación supone que las diferencias químicas o físicas entre las mezclas pigmentarias son el resultado de distintas preparaciones de pinturas, y estas probablemente respondan a eventos diferentes de confección de motivos sucedidos en el tiempo, posibles de ser conectados con otras líneas de evidencias (Gheco, Gastaldi et al., 2019).

Los estudios químicos fueron realizados sobre muestras provenientes de los distintos abrigos de Oyola y, fundamentalmente, de la cueva Oyola 7 (Gheco y Poliszuk, 2015; Tascon et al., 2016; Gheco, Tascon et al., 2019). Más allá de las dificultades y los límites propios de las técnicas empleadas (Microscopía Electrónica de Barrido con Análisis Elemental por Energía Dispersiva de Rayos X -SEMEDS-, Espectroscopía Infrarroja por Transformada de Fourier -FT-IR-, Difracción de Rayos X-XRD, Fluorescencia de Rayos X -XRF- y Espectroscopía Raman), creemos haber alcanzado algunos datos suficientes para afirmar que al interior del sitio, pero también dentro de las mismas cuevas, existen pinturas de tonalidades similares pero que presentan señales químicas diferentes. Este hallazgo nos permite indicar que dichas pinturas podrían haber sido el producto de distintos eventos de preparación y confección de motivos. Entre las metodologías de análisis utilizadas, en bulk y microestratigráficas, las últimas permitieron alcanzar mejores resultados dado que no solo nos indican los elementos o compuestos químicos presentes, sino también su localización precisa en las muestras.

A modo de ejemplo, podemos observar los datos obtenidos del análisis microestratigráfico de una muestra extraída de un motivo rojo presente en Oyola 7 (Figura 10). Como vemos, en la estratigrafía se advierten, cuando menos, tres o cuatro capas diferentes. Comenzando por la superior, la más externa, la primera capa roja corresponde al motivo muestreado, cuyos análisis Raman revelaron las señales características de la hematita y el yeso. Sin embargo, más abajo en la estratigrafía, notamos la presencia de un segundo estrato rojo de mayor intensidad, que no es visible a la observación directa actual dentro de la cueva como consecuencia de las múltiples capas que se depositaron sobre él. Al analizar este estrato mediante la misma técnica, obtuvimos solo las señales de la hematita. Por lo tanto, en este breve ejemplo -cuya complejidad excede por mucho estas líneas y será objeto de otros artículos- podemos advertir que en una misma cueva de Oyola existen pinturas de colores similares pero que son el resultado de preparaciones pigmentarias diferentes, correspondientes a momentos distintos de la historia del abrigo. De manera similar a las pinturas rojas, también hemos hallado diferencias químicas entre las figuras de tonos claros realizadas dentro de cueva, lo cual nos indica una pluralidad de mezclas pigmentarias resultantes de los sucesivos eventos de confección de motivos. 


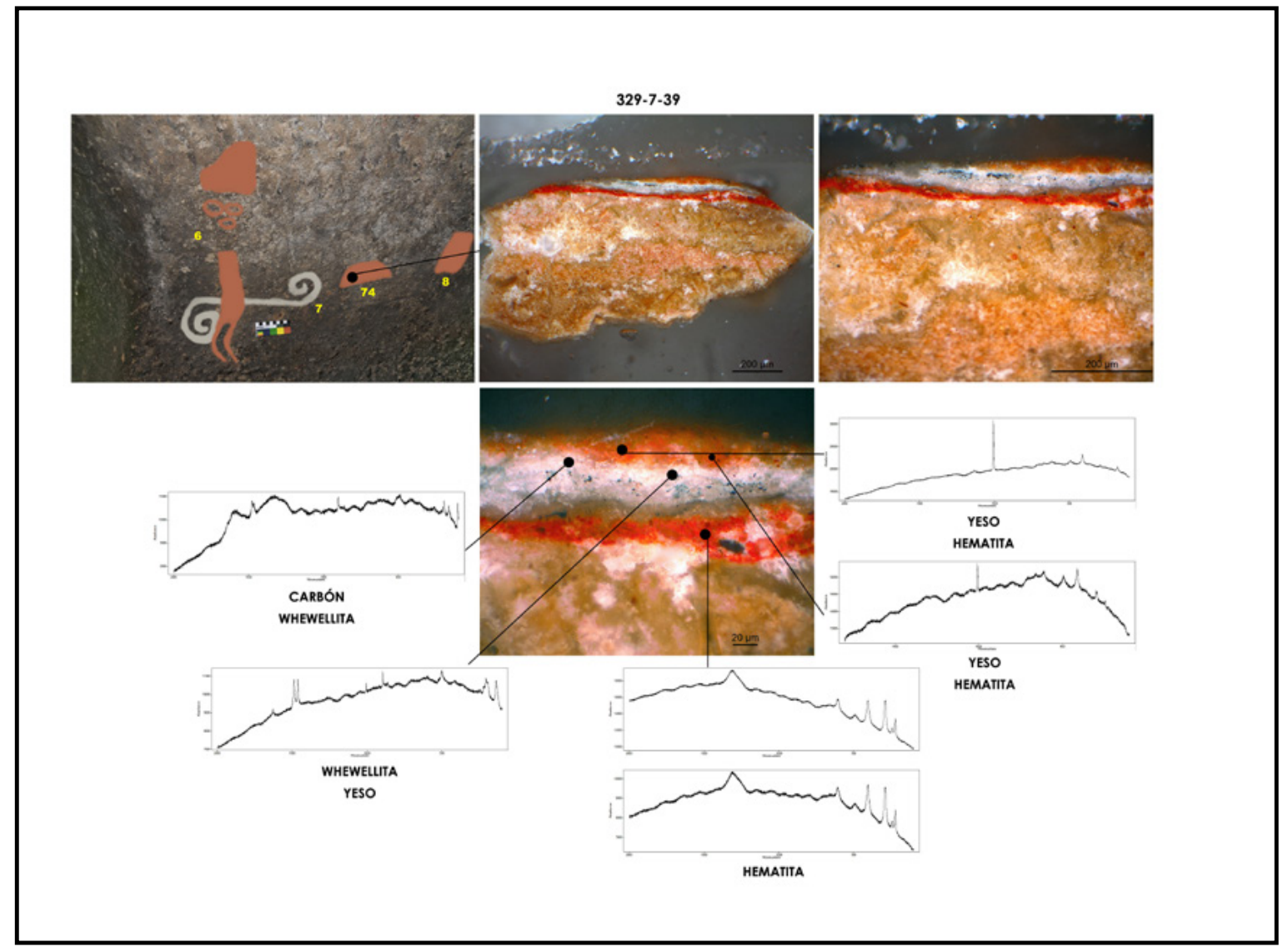

Figura 10. Ejemplo de las microestratigrafías analizadas en Oyola 7.

En particular, en esta muestra se observan dos capas rojas químicamente diferentes superpuestas y separadas entre sí por una capa de oxalatos de calcio y yeso, probablemente de origen natural.

\section{Discusión}

Comenzamos el artículo preguntándonos sobre el modo de aproximarnos a las historias de construcción de los paneles con arte rupestre y a las múltiples prácticas sociales desarrolladas en los aleros, cuevas o bloques rocosos. Como una forma de intentar responder a dichos interrogantes, presentamos el caso de estudio del arte rupestre de la sierra de El AltoAncasti y delineamos las principales características de una metodología focalizada en la investigación de las prácticas sociales que combina diferentes niveles de análisis con cinco líneas de evidencias. En otros trabajos planteamos una forma específica para interconectar entre sí cada una de estas técnicas de análisis a través de la detección de delgadas capas de hollín en las paredes de las cuevas, posibles de ser asociadas a los fogones documentados en la matriz de la excavación (Tascon et al., 2016; Gheco et al., 2017; Gheco, Gastaldi et al., 2019; Gheco, Tascon et al., 2019). Esta conexión brinda un punto de contacto importante para vincular determinados momentos en la historia de pintado de las paredes con episodios puntuales en la ocupación del abrigo, con la posibilidad de integrar el arte rupestre a las demás actividades desarrolladas en las cuevas.

Sin embargo, de modo más general, en este artículo deseamos concentrarnos en el potencial interpretativo que supone la metodología descripta. Como repasamos al iniciar el trabajo, las explicaciones sobre el arte rupestre de El Alto-Ancasti elaboradas a lo largo de varias décadas lo vincularon a una cultura o a un período en particular (Cultura La Aguada/Período Medio o de Integración Regional) y lo asociaron a una supuesta funcionalidad mágico/religiosa/ritual. 
De este modo, a pesar de existir ciertos indicios que apuntaban a una mayor diacronía y heterogeneidad, dichas explicaciones tendieron a elaborar interpretaciones más bien homogéneas y sincrónicas. No es nuestra intención debatir dicha adscripción cultural y funcional, sino más bien centrarnos en la diversidad de prácticas sociales eclipsadas detrás de estos conceptos generales e indagar en los distintos caminos para conocerlas.

La primera línea de evidencias transitada significó dejar de lado, al menos por un momento, las propias pinturas y grabados para centrarnos en las formas particulares en que la ubicación de dichos motivos estructura las acciones ejecutadas a su alrededor. De esta forma, definimos diferentes modalidades espaciales en que pueden clasificarse los distintos sitios con arte rupestre de la sierra; modalidades que expresan pautas de selección distintas de los espacios para ser pintados/grabados y con ello, probablemente, también prácticas sociales diferentes. De este modo comenzamos a advertir una diversidad mayor del arte rupestre de estas serranías, aunque en algunos casos las tensiones entre los fenómenos generales -como las modalidades definidas- y los casos específicos de cada uno de los abrigos que conforman muchos de los sitios arqueológicos nos obligaron a modificar este primer nivel de análisis de toda la sierra (nivel de paisaje) hacia un sitio en particular (Oyola). En este segundo nivel, el relevamiento de las mismas variables espaciales dio lugar a la definición de otras cuatro modalidades, pero en este caso solo para los abrigos de Oyola: 1) Pequeñas cuevas con pinturas que configuran entornos íntimos, oscuros y de escaso movimiento, alejados de los espacios residenciales y productivos; 2) grandes aleros o cuevas que permiten la observación simultánea de los motivos por parte de un elevado número de personas congregadas dentro de los abrigos e incluso desde las plataformas elaboradas en los accesos; 3) bloques y peñascos pintados muy próximos a los ríos, observables a la distancia al transitar por los márgenes de los cursos de agua, y 4) grandes rocas horizontales con grabados en surco profundo dispuestos cerca de las terrazas de cultivo y de las casas, donde los motivos son apreciados al situarse sobre ellos o en los metros próximos. Sin embargo, como vimos, a pesar de la diversidad de espacios con arte rupestre descriptos para Oyola, los análisis espaciales, y las modalidades definidas, tienden a presentar como recortes sincrónicos el producto de una historia de sucesivas transformaciones. Es por ello que decidimos indagar en otras técnicas que nos informen sobre la complejidad diacrónica del arte rupestre de este sitio, como el estudio de las superposiciones entre figuras y los análisis estilísticos.

Las superposiciones documentadas en Oyola, aunque escasas, nos enfrentaron a la naturaleza policrónica del arte rupestre del sitio. Este dato, junto a los obtenidos mediante los análisis estilísticos y químicos, confirma aquellas sospechas de una mayor complejidad temporal del arte rupestre de estas cuevas, factibles de ser interpretadas como obras abiertas continuamente transformadas (Quesada y Gheco, 2015). Pero, por otro lado, las características específicas de las superposiciones prehispánicas (milimétricas y entre pinturas de los mismos colores) y su escaso número nos sitúan frente a dinámicas de agregados de motivos en el tiempo cuyo producto final, siempre sujeto a nuevos cambios, no hace evidentes dichas modificaciones.

A partir de los estudios estilísticos intentamos evaluar, desde una perspectiva plástica y no prescriptiva, las similitudes entre determinadas figuras de camélidos y antropomorfos en Oyola, lo que dio lugar a la definición de cuatro modalidades o modos de hacer estos motivos que se reiteran en las distintas cuevas y abrigos del sitio. Estos estilos, en tanto resultados de la negociación práctica de las personas ante las rocas, pueden ser utilizados de manera muy cauta como indicadores cronológicos relativos, lo cual brinda otro indicio de la diacronía en la producción del arte rupestre de Oyola. Sin embargo, también resulta interesante advertir la particular distribución de estas modalidades en los abrigos de Oyola. Como mencionamos, más del $80 \%$ de los abrigos en donde fueron elaborados varios camélidos o antropomorfos, las figuras pueden incluirse en una sola modalidad y fueron realizadas en colores similares, a pesar de que muchas son el resultado de distintos eventos de pintado. De esta manera, en concordancia con los estudios de las superposiciones, las cuevas y aleros de Oyola nos devuelven una experiencia paradójica: abrigos modificados a lo largo del tiempo mediante el agregado de nuevas figuras, pero que conservan 
un aspecto de uniformidad y quietud que desvanece los cambios y los unifica en un mismo plano.

Por otro lado, los análisis químicos fueron utilizados como una vía de acceso alternativa a esta complejidad diacrónica, ya que fue posible identificar distintas preparaciones de pinturas de colores muy similares localizadas en las mismas cuevas. Estas mezclas pigmentarias químicamente disímiles habilitan a pensar en un número mayor de eventos de preparación de pinturas y de confección de motivos, lo cual concuerda con el resto de las líneas de evidencias descriptas.

La última línea de evidencias explorada, la excavación estratigráfica del piso de la cueva Oyola 7, expuso los diferentes episodios de mayor intensidad en el uso del abrigo, en los cuales se realizaron distintas actividades como el encendido de pequeños fogones y las últimas etapas en la manufactura de instrumentos líticos. Más allá de que estos datos deben ser estudiados con mayor profundidad, la información estratigráfica y los hallazgos materiales también permitieron plantear ciertas recurrencias en las actividades de cada uno de estos momentos, aunque dicha reiterabilidad en las prácticas posee algunas diferencias que nos advierten sobre la complejidad de dichos procesos.

En su combinación, los resultados de las cinco líneas de evidencias exploradas parecen contactarse en un punto: ellos exhiben los indicios de una historia en donde las cuevas y aleros con arte rupestre de Oyola fueron modificados una y otra vez; donde las paredes pintadas se transformaron en el tiempo, pero guardando un aspecto de uniformidad y quietud producto del agregado de nuevas figuras yuxtapuestas a las previas, de formas y colores similares, y evitando las superposiciones. Estos diferentes eventos de pintado fueron acompañados de otras tantas actividades que, a pesar de algunas diferencias, también se destacaron por sus recurrencias en cada ciclo de ocupación, como si existiese un correlato pragmático de la particular dinámica de transformaciones de los paneles con arte rupestre.

Ahora bien, ¿qué nos dicen estas similitudes en las prácticas sociales y en los repertorios pintados sobre las formas en que eran experimentados estos abrigos con arte rupestre? Resulta difícil no recordar las palabras de Levi-Strauss (2012 [1962]) al referirse a las sociedades frías, pueblos que hacen grandes esfuerzos por mitigar o invisibilizar los cambios históricos, en ocasiones recurriendo a un orden intemporal, en franca oposición a las sociedades calientes donde el cambio constante es la regla. ¿ Son estos indicios detectados en los abrigos con arte rupestre de Oyola el correlato material de las dinámicas de sociedades donde, justamente, el paso del tiempo es el elemento ausente? ¿Podrán configurar estas cuevas los espacios de apariencia invariable y primigenia donde se materializan los relatos míticos? ¿Qué experiencias y temporalidades producen y reproducen los abrigos de Oyola? Preguntas cuyas respuestas serán objetos de futuros trabajos, pero a las cuales no habríamos podido acceder sin intentar comprender las relaciones particulares entre el arte rupestre y las personas en perspectiva histórica.

Por último, ¿en qué medida esta metodología, datos y reflexiones son útiles para el estudio de otros contextos más allá de los límites de la sierra de El Alto-Ancasti? Si bien las secciones anteriores se refieren al estudio intensivo de un sitio en particular $y$, sobre todo de una cueva, creemos que esta experiencia puede resultar provechosa para (re)considerar dos puntos importantes en la investigación del arte rupestre.

En primer lugar, se destaca la necesidad de adoptar una perspectiva centrada en la investigación de las prácticas sociales y de los procesos históricos como una estrategia para acceder a la complejidad que suponen los abrigos con arte rupestre. Como vimos para el caso de El Alto-Ancasti, las investigaciones emprendidas a lo largo de varias décadas subrayaron su relativa homogeneidad mediante adscripciones estilísticas e interpretaciones funcionales uniformes. Sin embargo, al situar la atención en las historias concretas de algunos abrigos, comenzamos a advertir una diversidad mayor que trasciende la asignación cultural y nos sitúa ante las situaciones particulares en las cuales participaban las pinturas y grabados rupestres.

En segunda instancia, y en estrecha conexión con el punto anterior, creemos que esta experiencia puede resultar útil en la investigación de otros sitios en la 
medida en que expresa un esfuerzo metodológico por indagar en nuevas formas para acceder a dichas historias. Como intentamos exponer, pensamos que esta búsqueda no solo debe ser abordada como un problema técnico cuya resolución queda sujeta al empleo de cada vez más sofisticados procedimientos analíticos sino que, sobre todo, debe concentrarse en evaluar los datos obtenidos en las tensiones entre las tendencias generales y los casos particulares. Una metodología de múltiples niveles de análisis y varias líneas de evidencias permite complementar los fragmentos parciales de estas historias y poner en cuestión constantemente las conclusiones obtenidas, de modo de acceder a la diversidad y complejidad que supone todo proceso histórico. Así, antes que el arte rupestre "de una región", "de un estilo" o "de una cultura", las pinturas y grabados rupestres se erigen como agentes que producen, participan y son transformados por una diversidad de prácticas sociales a lo largo del tiempo.

\section{Agradecimientos}

Parte de este artículo constituye una síntesis de la tesis doctoral de quien suscribe. Por ese motivo, deseo agradecer especialmente la constante ayuda de los directores de ese trabajo, Marcos Quesada y Marcos Gastaldi, por sus pacientes lecturas y colaboración permanente, y al Consejo Nacional de Investigaciones Científicas y Técnicas (CONICET) por la Beca Doctoral (2012-2017) y Posdoctoral (20172019) que hizo posible la formación de posgrado. Del mismo modo, los resultados plasmados en este artículo no podrían haber sido logrados sin el apoyo de los distintos integrantes del Laboratorio 6 de la Escuela de Arqueología (UNCa) (Enrique Moreno, Gabriela Granizo, Soledad Meléndez, Carlos Barot, Maximiliano Ahumada, Débora Egea, Verónica Zucarelli, Antonela Nagel, Sofía Ferreyra, Sofía Quiroga y Sofía Boscatto) y de los investigadores del IIPC-TAREA (UNSAM) (Fernando Marte, Marcos Tascon, Noemí Mastrangelo, Florencia Castellá y Eugenia Ahets Etcheberry), del INTI (Rodrigo Álvarez, Andrés Ceriotti, Andrea Poliszuk, Sol Ugarteche y Soledad Pereda) y del Museo de Antropología (UNC) (Soraya López, Melisa Rodríguez Oviedo, Josefina Quiroga). Distintas instituciones financiaron las sucesivas etapas de este proyecto (Secretaría de Ciencia y Técnica, UNCa; CONICET, Agencia de Promoción Científica y Tecnológica (PICT 2017-2462 y PICT 2017-2589), Fondo Nacional de las Artes, National Geographic Society). La colaboración de los pobladores de Oyola y Vilismán resultó fundamental para este trabajo. Por último, los comentarios sugeridos por dos revisores anónimos y por el equipo editorial de la revista fueron muy valiosos para mejorar el manuscrito inicial.

\section{Referencias citadas}

Ahumada, M. (2016). Entre paisajes, animales y personas. Una historia desde El Taco 19 (Sierras de El Alto-Ancasti, Catamarca). (Trabajo Final de Licenciatura). Universidad Nacional de Catamarca, Catamarca, Argentina.

Ahumada, M., y Moreno, E. (2016). La escala doméstica y los Animales. Tratamiento diferencial de partes esqueletarias y distribución diferencial intra-sitio en El Taco 19 (El Alto-Ancasti, Catamarca). Anales de Arqueología y Etnología, 71, 105-117.

Aschero, C. (1988). Pinturas rupestres, actividades y recursos naturales; un encuadre arqueológico. En Yacobaccio, H., Borrero, L. A., García, L., Politis, G., Aschero, C. y Bellelli, C. (Eds.). Arqueología contemporánea Argentina. Actualidad y perspectivas (pp. 109-142). Buenos Aires: Ediciones Búsqueda.

Aschero, C. (1994). De cómo interactúan emplazamientos, conjuntos y temas. En Actas y Memorias del XI Congreso Nacional de Arqueología Argentina (pp. 17-28). San Rafael, Argentina.

Aschero, C. (1996). ¿A dónde van esos guanacos? En Gómez Otero, J. (Ed.). Arqueología. Sólo Patagonia (pp. 153-162).

Aschero, C. (2000). Figuras humanas, camélidos y espacios en la interacción circumpuneña. En Podestá, M. y De Hoyos, M. (Eds.). Arte en las rocas (pp. 16-54). Buenos Aires: Sociedad Argentina de Antropología.

Aschero, C. (2006). De cazadores y pastores. El arte rupestre de la modalidad Río Punilla en Antofagasta de la Sierra y la cuestión de la complejidad en la Puna meridional argentina. En Fiore, D. y Podestá, M. (Eds.). Tramas en la Piedra. Producción y Usos del Arte Rupestre (pp. 103140). Buenos Aires: Sociedad Argentina de Antropología, AINA, WAC. 
Barot, C. (2017). Las vasijas en la vida diaria. Análisis morfológico-funcional del material cerámico de una casa emplazada en las sierras de El Alto-Ancasti (siglos VII y VIII d.C.). (Trabajo Final de Licenciatura). Universidad Nacional de Catamarca, Catamarca, Argentina.

Basile, M. (2011). Continuidades y rupturas en las representaciones plásticas del Formativo (Ca. $200 \mathrm{Ad}$ ) a la ocupación Incaica (Ca. $1480 \mathrm{Ad}$ ) en la región de Fiambalá (Catamarca). (Tesis Doctoral). Universidad de Buenos Aires, Buenos Aires, Argentina.

Bednarik, R. G. (2002). The Dating of Rock Art: a Critique. Journal of Archaeological Science, 29(11), 1213-1233. https://doi.org/10.1006/jasc.2001.0711

Berenguer, J. (2004). Cinco milenios de arte rupestre en los Andes Atacameños: imágenes para lo humano, imágenes para lo divino. Boletín del Museo Chileno de Arte Precolombino, (9), 75-108.

Bonneau, A., Pearce, D. G. y Pollard, A. M. (2012). A multi-technique characterization and provenance study of the pigments used in San rock art, South Africa. Journal of Archaeological Science, 39(2), 287-294. https://doi. org/10.1016/j.jas.2011.09.011

Carandini, A. (1997). Historias en la tierra. Manual de excavación arqueológica. Barcelona: Crítica.

Carden, N. (2008). Imágenes a través del tiempo. Arte rupestre y construcción social del paisaje en la Meseta Central de Santa Cruz. Buenos Aires: Sociedad Argentina de Antropología.

Chippindale, C. (2004). From millimetre up to kilometre: a framework of space and of scale for reporting and studying rock art in its landscape. En Chippindale, C. y Nash, G. (Eds.). The figured landscapes of rock art: looking at pictures in place (pp. 102-117). Cambridge, MA: Cambridge University Press.

Criado-Boado, F. (1993). Visibilidad e interpretación del registro arqueológico. Trabajos de Prehistoria. DOI 10.3989/tp.1993.v50.i0.488

De la Fuente, N. (1969). "La Cultura de la Aguada: nuevos aportes para su estudio". Diario La Prensa.

De la Fuente, N. (1979). Nuevos descubrimientos de arte rupestre en la región de Ancasti, Provincia de Catamarca. Revista del Centro de Estudios de Regiones Secas.
De la Fuente, N. y Arrigoni, G. (1975). Arte Rupestre en la Región Sudeste de la Provincia de Catamarca. En Actas del Primer Congreso Nacional de Arqueología Argentina (pp. 177-203).

De la Fuente, N. y Díaz Romero, R. (1979). Algunos motivos del arte rupestre de la zona de Ancasti (Provincia de Catamarca). Revista Ampurias.

De la Fuente, N., Nazar, D. C. y Pelli, E. (2005). Documentación y diagnóstico del arte rupestre de La Tunita, Provincia de Catamarca, República Argentina. En Martín, S. y Gonaldi, M. (Eds.). La Cultura de La Aguada y sus Expresiones Regionales (pp. 227-244). La Rioja, Argentina: EUDELAR.

Didi-Huberrnan, G. (2008). Ante el tiempo. Historia del arte y anacronismo de las imágenes. Buenos Aires: Adriana Hidalgo editora.

Didi-Huberman, G. (2009). La imagen superviviente. Historia del arte y tiempo de los fantasmas según Aby Warburg. Madrid: Abada editores.

Edwards, H. G. M., Russell, N. C. y Seaward, M. R. D. (1997). Calcium oxalate in lichen biodeterioration studied using FT-Raman spectroscopy. Spectrochimica Acta Part A: Molecular and Biomolecular Spectroscopy, 53(1), 99-105. DOI 10.1016/S1386-1425(97)83013-2

Egea, D. M. (2015). Tallando en espacios rupestres. Tecnología litica en una cueva pintada del este catamarqueño (Trabajo Final de Licenciatura). Universidad Nacional de Catamarca, Catamarca, Argentina.

Fiore, D. (2009). La materialidad del arte. Modelos económicos, tecnológicos y cognitivos-visuales. En Barberena, R., Borrazzo, K. y Borrero, L. A. (Eds.). Perspectivas actuales en Arqueología Argentina (pp. 123-154). Buenos Aires: Dunken.

Fiore, D. (2018). The materiality of rock art: Image-making technology and economy viewed from Patagonia. En Troncoso, A., Armstrong, F. y Nash, G. (Eds.). Archaeologies of Rock Art: South American Perspectives (pp. 23-57) New York, NY: Routledge.

Gastaldi, M., Gheco, L., Moreno, E., Granizo, G., Ahumada, M., Egea, D. y Quesada, M. (2016). Primeros resultados de las excavaciones estratigráficas en Oyola 7 (Sierra 
de El Alto-Ancasti, provincia de Catamarca, Argentina). Comechingonia, 20(2), 73-104.

Gheco, L. (2012). Una historia en la pared. Hacia una visión diacrónica del arte rupestre de Oyola. (Tesis Final de Licenciatura). Universidad Nacional de Catamarca, Catamarca, Argentina.

Gheco, L. (2017). El laberinto de las paredes pintadas. Una historia de los abrigos con arte rupestre de Oyola, Catamarca. (Tesis Doctoral). Universidad Nacional de Córdoba, Córdoba, Argentina.

Gheco, L., Gastaldi, M., Marte, F., Quesada, M., Tascon, M. y Mastrangelo, N. (2017). About fires and paintings: Three stratigraphic insights on the history of a cave with prehispanic rock art. Journal of Archaeological Science: Reports, 15(May), 48-58.

Gheco, L., Gastaldi, M., Mastrangelo, N., Quesada, M., Marte, F. y Tascon, M. (2019). Entre humos, fuegos y pinturas. Una metodología para conectar historias sobre una cueva con arte rupestre del sitio de Oyola (Catamarca, Argentina). Boletín del Museo Chileno de Arte Precolombino, 24(1), 131-152.

Gheco, L. y Poliszuk, A. (2015). Caracterización química de pinturas rupestres prehispánicas del sitio arqueológico de Oyola mediante SEM-EDS, DRX, FT-IR, FRX y GC-MS (Catamarca, Argentina). En Pifferetti, A. A. y Dosztal, I (Eds.). Arqueometría argentina, metodologías cientificas aplicadas al estudio de los bienes culturales: datación, caracterización, prospección y conservación (pp. 271284). Buenos Aires: Aspha.

Gheco, L. y Quesada, M. (2012). El arte rupestre de Oyola (Dpto. El Alto, Catamarca): un caso de narrativas superpuestas. Aportes Científicos Desde Humanidades (UNCa), 9, 228-244.

Gheco, L., Quesada, M., Ybarra, G., Poliszuk, A. y Burgos, O. (2013). Espacios rupestres como obras abiertas: una mirada a los procesos de confección y transformación de los abrigos con arte rupestre del este de Catamarca (Argentina). Revista Española de Antropología Americana, 43(2). DOI 10.5209/rev_REAA.2013.v43.n2.44014

Gheco, L., Tascon, M., Gastaldi, M., Ahets Etcheberry, E., Pereda, S., Mastrangelo, N. y Marte, F. (2019). Hidden paintings, forgotten histories: a micro-stratigraphic approach to study coated rock art. Archaeological and Anthropological Sciences, 11, 5037-5052.

Ginzburg, C. (2008a). El queso y los gusanos. El cosmos según un molinero del siglo XVI. Barcelona: Península.

Ginzburg, C. (2008b). Mitos, emblemas, indicios. Morfologia e historia. México: Gedisa.

Ginzburg, C. (2010). El hilo y las huellas. Lo verdadero, lo falso, lo ficticio. Buenos Aires: Fondo de Cultura Económica.

González, A. R. (1977). Arte precolombino de la Argentina. Buenos Aires: Filmediciones Valero.

González, A. R. (1998). Cultura La Aguada. Arqueología y diseños. Buenos Aires: Filmediciones Valero.

Gordillo, I. (2009). Dominios y recursos de la imagen. Iconografía cerámica del valle de Ambato. Estudios Atacameños. Arqueología y Antropología Surandinas, 37, 99-121. DOI 10.4067/S0718-10432009000100007

Gordillo, I., Baldini, M. y Kusch, F. (2000). Entre objetos, rocas y cuevas: significados y relaciones entre la iconografía rupestre y mobiliar de Aguada. En Podestá, M. M. y De Hoyos, M. (Eds.). Arte en las Rocas. Arte Rupestre, Menhires y Piedras de Colores en Argentina (pp. 101-111). Buenos Aires: Sociedad Argentina de Antropología.

Gramajo, A. y Martínez Moreno, H. (1978). Otros Aportes al Arte Rupestre del Este Catamarqueño. Antiquitas, XXVI-XXVII, 12-17.

Gramajo, A., y Martínez Moreno, H. (1982). Otros aportes al arte rupestre del este catamarqueño. Museo Arqueológico Emilio y Duncan Wagner, 3, 77-88.

Harris, E. C. (1991). Principios de estratigrafía arqueológica. Barcelona: Crítica.

Hedges, R. E. M., Ramsey, C. B., Klinken, G. J. V. A. N., Nielsen, C., Etchegoyen, A., Niello, J. D. F., ... Llamazares, A. M. (1998). Methodological Issues in the $14 \mathrm{C}$ Dating of Rock Paintings. $16^{\text {th }}$ International $14 \mathrm{C}$ Conference. Radiocarbon, 40(1), 35-44.

Hernández Llosas, M. I. (1985). Diseño de una guía para el relevamiento y clasificación de datos de sitios arqueológicos con arte rupestre. Estudios en arte rupestre. Museo Chileno de Arte Precolombino, 25-36. 
Hodder, I. (1990). Style as historical quality. En Conkey y Hastorf (Eds.). The uses of style in archaeology. Cambridge, MA: Cambridge University Press.

Hodder, I. (1992). Theory and Practice in Archaeology. London: Routledge.

Jones, A. (2004). Archaeometry and materiality: materialsbased analysis in theory and practice. Archaeometry, 3(46), 327-338.

Kligmann, D. M. y Falchi, M. P. (2018). La imagen de la lagartija en la iconografía prehispánica del Noroeste Argentino I: una propuesta tipológica. Estudios Atacameños. Arqueología y Antropología Surandinas, 60, 97-131. DOI 0.4067/s0718-10432018005001404

Kusch, F., Hoffmann, M. y Abal, C. (2000). Portezuelo. Variabilidad estilística en torno a la iconografía humanofelínica durante el período formativo (Catamarca y La Rioja). Un enfoque interdisciplinario desde la Plástica y la Arqueología). Anti, 1(3), 11-23.

Lagrou, E. (2010). Arte ou artefato ? Agência e significado nas artes indígenas. Revista Proa, 01(2), 1-26.

Ledesma, R. (2012). El arte rupestre como expresión gráfica en las microregiones Cafayate y Santa Bárbara (Salta). Comechingonia, 16(1), 129-146.

Lema, V., Andreoni, D., Capparelli, A., Ortiz, G., Spano, R., Quesada, M. y Zorzi, F. (2015). Protocolos y avances en el estudio de residuos de pipas arqueológicas de Argentina. Aportes para el entendimiento de metodologías actuales y prácticas pasadas. Estudios Atacameños. Arqueología y Antropología Surandinas, 51, 77-97.

Lepetit, B. (2015). De la escala en historia. En Revel, J. (Ed.). Juegos de escalas. Experiencias de microanálisis. San Martín: UNSAM Edita.

Lévi-Strauss, C. (2012). El pensamiento salvaje. Buenos Aires: Fondo de Cultura Económica.

Llamazares, A. M. (1999). Arte rupestre de la cueva de La Candelaria, Provincia de Catamarca. Publicaciones de Arqueologia, 50.

Llamazares, A. M. y Slavutsky, R. (1990). Paradigmas estilísticos en arqueología: del normativismo culturalista a las alternativas postsistémicas. Boletin de Antropología Americana, 22, 21-43.
López, M., De la Fuente, G. y Fiore, D. (2013). Arqueometría del Arte: Estudios Fisicoquímicos de Pigmentos Arqueológicos. Boletín del Museo Chileno de Arte Precolombino, 17(4700), 75-81.

Loubser, J. (1984). Layer by layer: precision and accuracy in rock art recording and dating. En Blundell, G., Chippindale, C. y Smith, B. (Eds.). Seeing and Knowing. Rock Art with and without Ethnography (pp. 149-167). Gauteng, Sudáfrica: Wits University Press.

Martel, Á. (2010). Arte rupestre de pastores y caravaneros. Estudio contextual de las representaciones rupestres durante el periodo agroalfarero Tardio (900 d.C. - 1480 d.C.) en el Noroeste Argentino. (Tesis Doctoral). Universidad de Buenos Aires: Buenos Aires, Argentina.

Martel, Á., Rodríguez Curletto, S. y Del Bel, E. (2012). Arte Rupestre y Espacios de Memoria: Las Representaciones del Sitio Confluencia (Antofagasta de la Sierra, Catamarca, Argentina). Revista Chilena de Antropología, 25(4000), 121-162.

Moore, J. D. (2010). Making a huaca: Memory and praxis in prehispanic far northern Peru. Journal of Social Archaeo$\log y, 10(3), 398-422$. DOI 10.1177/1469605310381550

Moreno, E. y Quesada, M. (2012). Análisis preliminar del conjunto arqueofaunístico de El Taco 19, Sierras de El Alto-Ancasti, Catamarca. Comechingonia, 16(2), 173179.

Nash, G. (2002). The landscape brought within, a re-evaluation of the rock painting site at Tumlehed, Torslanda, Goteborg, west Sweden. En Nash, G. y Chippindale, C. (Eds.). European landscapes of rock art (pp. 176-194). Cambridge, MA: Cambridge University Press.

Nazar, D. C., De la Fuente, G. y Gheco, L. (2014). Entre cebiles, cuevas y pinturas. Una mirada a la estética antropomorfa del arte rupestre de La Tunita, Catamarca, Argentina. Boletin del Museo Chileno de Arte Precolombino, 19(1), 37-51.

Nazar, D. C., Gheco, L. y Barot, C. (2012). Avances en la documentación del sitio La Tunita (Catamarca, Argentina). Comechingonia, 16, 299-308.

Pauketat, T. R. (2001). Practice and history in archaeology: An emerging paradigm. Anthropological Theory, 1(73), 73-98. DOI 10.1177/1469962002002002628 
Pauketat, T. R. y Alt, S. M. (2005). Agency in a postmold? Physicality and the archaeology of culture-making. Journal of Archaeological Method and Theory, 12(3), 213-237. DOI 10.1007/s10816-005-6929-9

Quesada, M. y Gheco, L. (2011). Modalidades espaciales y formas rituales. Los paisajes rupestres de El Alto-Ancasti. Comechingonia, 15, 63-83.

Quesada, M. y Gheco, L. (2015). Tiempos, cuevas y pinturas. Reflexiones sobre la policronía del arte rupestre de Oyola (Provincia de Catamarca, Argentina). Relaciones de la Sociedad Argentina de Antropología, 2(XL), 455-476.

Quesada, M. N., Gastaldi, M. R. y Granizo, G. M. (2012). Construcciones de periferias y producción de lo local en las cumbres de El Alto-Ancasti. Relaciones de la Sociedad Argentina de Antropologí, 37(2), 435-456.

Quesada, M., Zuccarelli, V., Gheco, L., Gastaldi, M. y Boscatto, S. (2016). Paisaje y experiencia en Oyola a finales del primer milenio D.C. (Dpto. El Alto, Catamarca). Comechingonia, 20(2), 13-42.

Re, A. (2016). Superimpositions and attitudes towards preexisting rock art: a Case Study in Southern Patagonia. En Bednarik, R. G., Fiore, D., Basile. M. y Kumar, G. (Eds.). Paleoart and materiality. The scientific study of rock art (pp. 15-30). Oxford: Archaeopress.

Revel, J. (2015). Microanálisis y construcción de lo social. In Juegos de escalas. Experiencias de microanálisis. Buenos Aires: Universidad Nacional de San Martín.

Rogerio Candelera, M. Á. (2014). Análisis digital de imágenes, caracterización de pigmentos y matrices de Harris. Un enfoque integrado para el registro de las superposiciones de paneles pictóricos rupestres. En Medina-Alcaide, M. A. y Romero, A. (Eds.). Mensajes desde el pasado. Manifestaciones gráficas de las sociedades prehistóricas. Madrid.

Ruiz, J. F., Hernanz, A., Armitage, R. A., Rowe, M. W., Viñas, R., Gavira-Vallejo, J. M. y Rubio, A. (2012). Calcium oxalate AMS $14 \mathrm{C}$ dating and chronology of postPalaeolithic rock paintings in the Iberian Peninsula. Two dates from Abrigo de los Oculados (Henarejos, Cuenca, Spain). Journal of Archaeological Science, 39(8), 26552667. DOI 10.1016/j.jas.2012.02.038
Runcio, M. (2007). El estilo en arqueología: diferentes enfoques y perspectivas. Revista Espacios de Critica y Producción, 36, 18-28.

Russ, J., Hyman, M. y Rowe, M. (1992). Direct Radiocarbon Dating of Rock Art. Radiocarbon, 34(3), 867-872.

Russell, T. (2000). The Application of the Harris Matrix to San Rock Art at Main Caves North, Kwazulu-Natal. The South African Archaeological Bulletin, 55(171), 60-70. DOI $10.2307 / 3888893$

Schobinger, J. y Gradin, C. (1983). Arte rupestre de la Argentina. Cazadores de la Patagonia y agricultores andinos. Madrid: Encuentro.

Segura, Á. (1971). Pictografías de Catamarca. Separata de la Revista de La Junta de Estudios Históricos de Catamarca, 1962-1968. Catamarca, Argentina.

Sepúlveda, M. (2004). Esquemas visuales y emplazamiento de las representaciones rupestres de camélidos del Loa superior en tiempos incaicos. ¿Una nueva estrategia de incorporación de este territorio al Tawantinsuyu? Chungara. Revista de Antropología Chilena, 36(2), 439-451.

Sepúlveda, M. (2011). Pinturas rupestres y tecnología del color en el extremo sur de Chile. Magallania, 39(1), 193210. DOI 10.4067/S0718-22442011000100012

Tascon, M., Mastrangelo, N., Gheco, L., Gastaldi, M., Quesada, M. y Marte, F. (2016). Micro-spectroscopic analysis of pigments and carbonization layers on prehispanic rock art at the Oyola's caves, Argentina, using a stratigraphic approach. Microchemical Journal, 129. DOI 10.1016/j.microc.2016.07.003

Troncoso, A. (2005). Hacia una semiótica del arte rupestre de la cuenca superior del río Aconcagua, Chile central. Chungara. Revista de Antropología Chilena, 37(1), 21-35. DOI 10.4067/S0717-73562005000100003

Troncoso, A. (2008a). Arquitectura imaginaria y ritualidad del movimiento: arte rupestre y espacio en el cerro Paidahuen, Chile Central. En Acuto, F. y Zaranquin, A. (Eds.). Sed non Satiata II (pp. 277-301). Córdoba, Argentina: Editorial Brujas.

Troncoso, A. (2008b). Spatial syntax of rock art. Rock Art Research, 25(1), 3-12. 
Troncoso, A. (2012). Arte rupestre y camélidos en el norte semiárido. Boletín del Museo Chileno de Arte Precolombino, 17(1), 75-93.

Troncoso, A., Moya, F., Sepúlveda, M. y Carcamo, J. J. (2015). First absolute dating of Andean hunter-gatherer rock art paintings from North Central Chile. Archaeological and Anthropological Sciences. DOI 10.1007/s12520015-0282-z
Yacobaccio, H. D., Cata, M. P., Sola, P. y Alonso, M. S. (2008). Estudio arqueológico y fisicoquímico de pinturas rupestres en Hornillos 2 (Puna de Jujuy). Estudios Atacameños. Arqueología y Antropología Surandinas, 36, 5-28. DOI 10.4067/S0718-10432008000200002

(c) (i) Este es un artículo de acceso abierto bajo licencia Creative Commons Reconocimiento 4.0 Internacional 